\title{
Characterization of Hybrid Composites with Polyester Waste Fibers, Olive Root Fibers and Coir Pith Micro-Particles Using Mixture Design Analysis for Structural Applications
}

\author{
Muhammad Rizwan Tufail ${ }^{1}$, Hafsa Jamshaid ${ }^{1}$, Rajesh Mishra ${ }^{2, *(D)}$, Uzair Hussain ${ }^{1}$, Martin Tichy ${ }^{2}$ (D) \\ and Miroslav Muller ${ }^{2}$ D \\ 1 Faculty of Textile Engineering, National Textile University, Faisalabad 37610, Pakistan; \\ formanite819@gmail.com (M.R.T.); hafsa@ntu.edu.pk (H.J.); uzair@ntu.edu.pk (U.H.) \\ 2 Department of Material Science and Manufacturing Technology, Faculty of Engineering, \\ Czech University of Life Sciences Prague, Kamycka 129, 16500 Prague 6-Suchdol, Czech Republic; \\ martintichy@tf.czu.cz (M.T.); muller@tf.czu.cz (M.M.) \\ * Correspondence: mishrar@tf.czu.cz
}

\section{check for} updates

Citation: Tufail, M.R.; Jamshaid, H.; Mishra, R.; Hussain, U.; Tichy, M.; Muller, M. Characterization of Hybrid Composites with Polyester Waste Fibers, Olive Root Fibers and Coir Pith Micro-Particles Using Mixture Design Analysis for Structural Applications. Polymers 2021, 13, 2291. https://doi.org/ $10.3390 /$ polym 13142291

Academic Editor: Fabrizio Sarasini

Received: 10 June 2021

Accepted: 12 July 2021

Published: 13 July 2021

Publisher's Note: MDPI stays neutral with regard to jurisdictional claims in published maps and institutional affiliations.

Copyright: (c) 2021 by the authors. Licensee MDPI, Basel, Switzerland. This article is an open access article distributed under the terms and conditions of the Creative Commons Attribution (CC BY) license (https:/ / creativecommons.org/licenses/by/ $4.0 /)$.

\begin{abstract}
In the present work, hybrid composites were developed by using polyester waste fibers along with natural origin materials: olive root fibers and coir pitch filler. Such composite panels can be used as a potential alternative for fiber glass sunshade panels and room dividers in buildings. Hybrid composites were fabricated by mixing polyester waste fibers and olive root fibers in different ratios (0:100, 33:67, 67:33 and 100:0). Coir pith micro-particles with an average size of 312 d.nm were used as filler in the polyester matrix at three different levels $(0 \%, 5 \%$, and $10 \%)$ of the overall matrix weight. Mechanical properties, e.g., tensile strength, flexural strength and impact strength, thermal properties, e.g., coefficient of linear thermal expansion, thermo-gravimetric analysis (TGA) and environmental properties, e.g., water absorption, loss of density after exposure to weathering were characterized. For comparison purposes, a commercially available fiber glass sunshades sample was also investigated. Mixture design analysis was used to optimize the ratio of all components in the composite. Graphical comparison of experimental results using regression models showed a high degree of correlation. An optimized formulation of composite with an objective of maximization of tensile strength, flexural strength, impact strength and minimization of water absorption, density loss, as well as coefficient of linear thermal expansion, was determined at $70.83 \mathrm{wt} \%, 15.15 \mathrm{wt} \%$, and $14.01 \mathrm{wt} \%$ of polyester waste fibers, olive root fibers and coir pith micro-fillers, respectively. Overall, it can be concluded that the developed hybrid composites from waste fibrous materials can be used as a promising alternative and a value-added application in buildings and construction purposes.
\end{abstract}

Keywords: hybrid composite; polyester waste fiber; olive root fiber; coir pith filler; building materials; mixture design analysis

\section{Introduction}

Composite material performance and properties depend on the properties of individual components, mixture proportions and their inter-facial compatibility. The composite materials primarily consist of two constituents, one of which is the reinforcement material that could be treated with chemicals for surface modification [1] in order to improve binding and handling properties. The second component is the matrix which serves to protect the reinforcement material from environmental and external damage by transfer of the load [2]. In addition, they may contain a third component called "fillers" which are mixed with polymeric matrix in order to improve its mechanical and thermal properties. Fillers are used for reducing the overall weight and cost of the composite while enhancing its performance [3,4]. Natural fiber-based composites are environmentally superior in specific fields of application [5]. The global interest in natural fiber-based composites is growing 
because they are alternatives for synthetic or man-made fibers such as glass or carbon [6]. Natural fiber reinforcements are a renewable resource, and their production requires little energy. They have very low carbon dioxide emissions and are not dependent on petroleumbased precursors. Sisal, bamboo, jute, and coir are widely used as engineering materials in different industries $[7,8]$.

A proper material design helps in achieving a balance in performance and cost for application in numerous fields ranging from the building industry to the automobile industry $[9,10]$. Recently, different industries are looking into the replacement of polymer or glass fiber composites. The natural fiber-based composites have relatively lower mechanical performance and higher water absorption properties compared to the glass or carbon fiberbased composites. Therefore, a hybrid fabrication method is used to produce composite products with improved mechanical, thermal, water resistance, and water absorption properties. In this technique, composite materials are manufactured by using two or more reinforcing materials in a single matrix or two polymers blended matrices with single natural fiber reinforcement. The reinforcing materials can be made of natural or synthetic fibers depending on the required performance level [11,12]. Polyester fibers are consumed in different textile applications. Their origin is from petroleum-based materials which are not sustainable, and their biodegradability is another issue. Polyester waste fibers can be recycled in order to reduce environmental pollution by not putting them into landfills. That would prevent the chemicals from leaching into the soil. Reusing is another option that is more energy-efficient than recycling, especially when it can be used for value-added products. Franciszczak et al. revealed that the injection-molded composite of short PET fibers reinforced to PETG (Polyethylene terephthalate glycol) matrix display good impact strength on the same level of polypropylene reinforced by glass fibers [13]. Wu et al. determined that the self-reinforced PET composite of high tenacity PET as reinforcement and copolymerized PET as matrix show excellent flexural and impact behavior [14]. Ahmad et al. studied the composite of hybrid fabric by the interlacement of warp (hemp yarn) and weft (PET yarn) produced by vacuum infusion process with epoxy resin. Such composites display an enhancement in tensile strength [15]. Composite samples were produced from six layers of woven kenaf fabrics arranged at symmetric angles $\left(0^{\circ}\right.$, $45^{\circ}, 90^{\circ}$ ) and impregnated with PET in POM (Polyoxymethylene) matrix. The hybrid composite samples showed increases in the modulus and strength [16]. Wu et al. studied that self-reinforced PET composite of recycled PET homopolymer filaments serving as the reinforcements and copolymerized PET (mPET) filaments as the matrix exhibit improved resistance to creep deformation [17]. Composites prepared by hand layup and compression molding of coir pith/nylon/epoxy showed that chemical treatment improves the water resistance and offers optimum retention of impact strength in composites [18]. Essabir et al. developed polypropylene hybrid composites by using coir fibers and coir shell microparticles under injection molding. The findings indicate that coir shell particles have low thermal degradation compared to coir fiber [19]. Islam et al. concluded that hand layup of coir mat/polyester composite with coir powder as filler with varying content of $(10,20,30$, 40,50 , and $100 \%$ ) shows an improvement in mechanical properties up to $30 \%$ and further addition of filler results in deterioration of mechanical properties [20]. Hybrid composite with coir pith/nylon fabric/epoxy made by hand lay-up showed that $\mathrm{NaOH}$ treatment of coir pith increases the composite's impact strength and water resistance [21,22]. A hybrid composite of coir pith, rice husk, and groundnut shell was prepared with epoxy resin. The results revealed that the hybridization of micro-particles greatly influenced the tensile and flexural properties of the composites [23,24]. Composites based on recycled PET fibers with an average length of (2 to $20 \mathrm{~mm}$ ) in the polyester matrix exhibited good dispersion, interfacial adhesion, and high affinity of PET fibers with matrix leading to improved mechanical performance [25]. Abdulla et al. developed the hybrid composite of kenaf and PET fibers reinforced POM using compression molding technique and exposed the samples to ultraviolet penetration, moisture, and water spray in the weathering chamber. The increasing PET contents indicated better retention in mechanical properties when 
exposed to UV and moisture as compared to natural fiber-rich composites. Thus, hybrid composites are more suitable for outdoor applications [26]. The hybrid composite of kenaf/PET fiber in the POM (polyoxymethylene) matrix was investigated to study the mechanical as well as moisture absorption properties. The impact strength of composites using longer fibers was found to be higher than composites reinforced with short fibers [27]. Studies on composites reinforced with glass fibers, waste polyethylene terephthalate fibers and kenaf fibers developed by compression molding concluded that the tensile strength of glass fiber-reinforced PET waste and kenaf hybrid composites was higher than the pure PET waste composites. They can be used for construction materials like wall and partition materials [28]. The injection-molded polypropylene composites were prepared with distinct mixtures of the wood flour and the olive mill sludge (OMS). With increasing olive mill sludge, the water-resistance of composites increases. However, the flexural characteristics deteriorate with the increase in OMS flour content [29].

Mixture design analysis is used where the response depends on mixture proportions of various components and not on the absolute amount of incorporating materials. For example in an alloy, the mechanical properties may depend on variable proportions of the various metals but not on the absolute amount of each component. The mixture design experiments are widely used nowadays in order to determine the optimum formulation of various components and blending ratios in multicomponent composite materials. The specific objective is to determine, analyze and optimize the most preferred mixture proportion in a composite product at the lowest price [30,31].

The main aim of this research is to analyze the effect of polyester waste fibers, olive root fibers as reinforcement and coir pith as filler on the mechanical properties (tensile strength, flexural strength and impact strength), weathering effects (water absorption and density loss) and the thermal properties (coefficient of linear thermal expansion and thermogravimetric analysis) of hybrid composites based on a polyester matrix. After modeling the mixture design, the aim is to determine the optimized component proportion for the experimental responses through maximizing and minimizing each component. The mixture design analysis was applied through Minitab statistical software in order to model the relationship between input variables and the experimental responses.

\section{Materials and Methods}

\subsection{Materials}

Polyester waste fibers of varying length in the range of 2-5 $\mathrm{mm}$ was provided by Diamond export industries Pvt. Ltd., Jaranwala Road, Khurrianwala, Faisalabad, Pakistan. This waste was removed in the rinsing process during the manufacturing of fabric. Olive root sticks were procured from a local market in Faisalabad, Pakistan. The olive root fibers were obtained by beating/pressing the sticks and extracting the fibers manually. The fibers were cut into a staple of 2-5 mm. Coconut husk was collected from local vendors and was dried under the sun to remove the moisture from them. The raw materials used are shown in Figure 1.

The coir pith was extracted manually and cleaned from dust and dirt by washing with distilled water. Fibers were chopped into $2 \mathrm{~mm}$ length. Selected samples were treated with $2 \% \mathrm{NaOH}$ solution for $4 \mathrm{~h}$ at room temperature. Further, the alkali-treated samples were thoroughly washed with distilled water, so as to leave no trace of alkali. The alkali treatment removes pectins, fats, lignin and hemicellulose from the fiber, thereby increasing the percentage of cellulose content. This also improves the adhesivity of coir surface with the resin in a composite. In order to obtain the required particle size, alkali-treated coir pith was subjected through the ball mill process as shown in Figure 2. Z-average size of ball-milled coir pith micro-particles was measured to be $312 \mathrm{~d}$.nm as per stander protocol on Malvern-zeta sizer. 

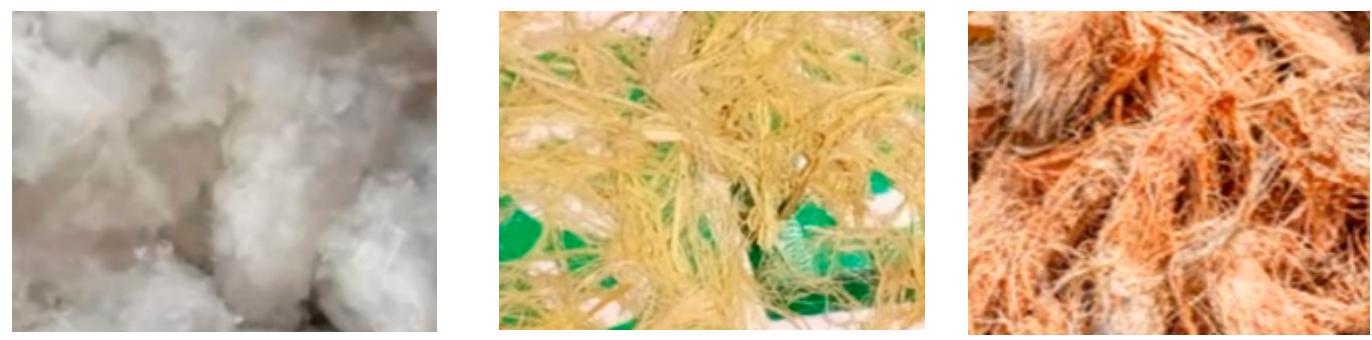

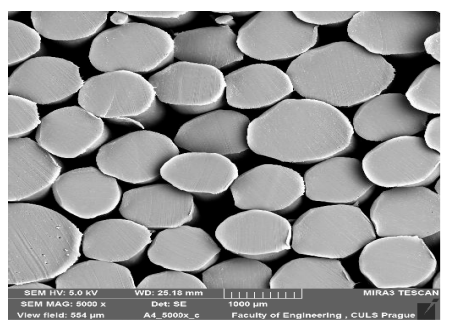

(a) PET fibers

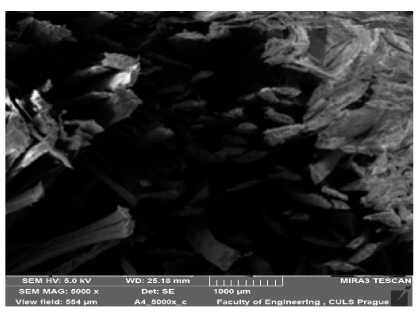

(b) Olive root fibers

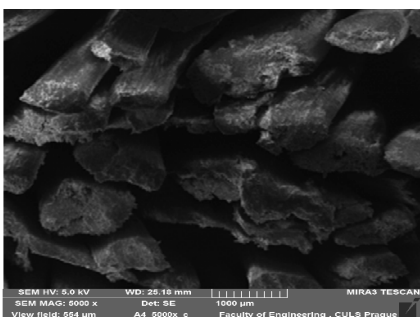

(c) Coir pith fibers

Figure 1. SEM images of fibers used.

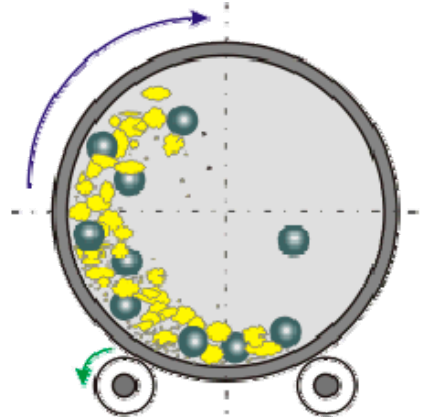

(a) Ball milling

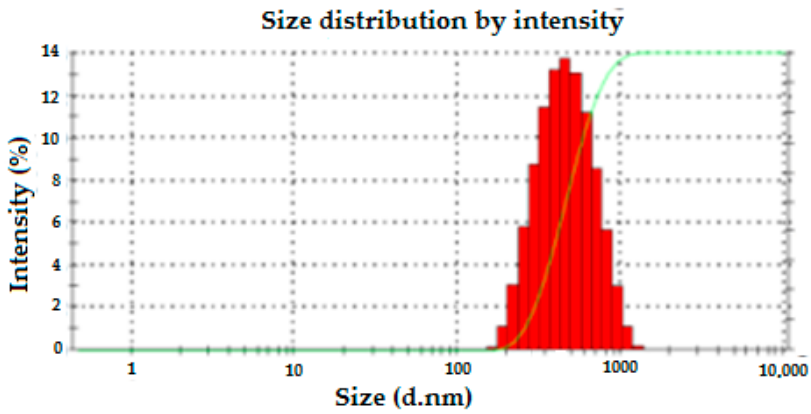

(b) Micro-particle size distribution

Figure 2. Ball milling to prepare coir pith micro-particles.

The commercially available unsaturated polyester resin was obtained from Changzhou Rixin Resin Co., Ltd., China. Unsaturated polyester resin is a thermosetting polymer, which is chemically similar to epoxy resin and vinyl ester resins. It has excellent and long-term durability to water. It offers adequate resistance to different chemicals, to a large range of substances, from vegetable oil to sulfuric acid. The list of some chemicals' resistance along their resistive level is shown in Table 1.

Table 1. Resistance against different chemicals.

\begin{tabular}{cc}
\hline Chemicals & Resistance Level \\
\hline Dilute acid & +++ \\
Dilute alkalis & +++ \\
Oil and greases & ++ \\
Aliphatic hydrocarbons & + \\
Aromatic hydrocarbons & + \\
Halogenated hydrocarbons & + \\
Alcohols & +++ \\
\hline
\end{tabular}

Resistance levels: ++++ very good, +++ good, ++ moderate, + poor. 
Unsaturated polyester resin also exhibits adequate resistance against extreme weathering conditions like rain, ice, snow, strong winds, high temperature, and UV rays. The physical, mechanical and thermal properties of polyester resin are given in Table 2.

Table 2. Properties of unsaturated polyester resin.

\begin{tabular}{cc}
\hline Properties & Value \\
\hline Physical State & Liquid at $25^{\circ} \mathrm{C}$ \\
Color & Yellowish \\
Density, g/ $\mathrm{cm}^{3}$ & 1.12 at $2{ }^{\circ} \mathrm{C}$ \\
Viscosity, mPoise & $300-600$ at $25^{\circ} \mathrm{C}$ \\
Storage Temperature & $15-25^{\circ} \mathrm{C}$ \\
Barcol Hardness & 40 \\
Tensile Strength, MPa & 12 \\
Tensile Modulus, GPa & 2.1 \\
Elongation at break, $\%$ & 2.1 \\
Flexural Strength, MPa & 25 \\
Flexural Modulus, GPa & 0.9 \\
Heat deflection temperature (HDT, $1.80 \mathrm{MPa}),{ }^{\circ} \mathrm{C}$ & 80 \\
Glass transition temperature $(\mathrm{Tg}),{ }^{\circ} \mathrm{C}$ & $115-120$ \\
\hline
\end{tabular}

COBALT was used as an initiator and methyl ethyl ketone peroxide (MEKP) as a curing agent were procured from local market.

\subsection{Methods}

Twelve samples of hybrid composites were prepared with different compositions of reinforcement materials by weight percentage as given in Table 3 of the experiment design. The mold of size ( $340.8 \mathrm{~mm} \times 340.8 \mathrm{~mm} \times 3 \mathrm{~mm})$ was used, and mold-releasing wax was applied to it before developing the samples. Polyester waste fibers and olive root fibers were blended in different ratios (0:100, 33:67, 67:33 and 100:0). The reinforcing fibers were loaded as per the required blend ratio and were arranged in the form of a matt inside the mold. The unsaturated polyester resin was mixed with $1 \mathrm{wt} \%$ COBALT as an accelerator and $0.5 \mathrm{wt} \%$ ethyl methyl ketone peroxide (EMKP) as a matrix curing agent. Coir pith micro-particles were used as filler in the polyester matrix at three different levels $(0 \%, 5 \%$, and $10 \%$ ) of the overall matrix weight. The matrix with micro-particles was poured and applied by the hand lay-up method. The total aggregate of the loaded mixture components of polyester waste fibers $(X p)$, olive root fibers (Xo), and coir pith $\left(X_{c}\right)$ is equal to $100 \mathrm{wt} \%$ as shown in Table 3. After impregnation, the specimens were subjected to compression molding, under a pressure of $10 \mathrm{~kg} / \mathrm{cm}^{2}$ at a temperature of $100^{\circ} \mathrm{C}$ for $15 \mathrm{~min}$. All samples were stored post-curing at room temperature for $24 \mathrm{~h}$, and then cut into required testing specimens. For all the samples, a thickness of $3 \pm 0.1 \mathrm{~mm}$ was maintained. The commercial fiber glass sample which was used for comparison purposes also has the same thickness.

Table 3. Design of experiment.

\begin{tabular}{cccc}
\hline Samples & $\boldsymbol{X} \boldsymbol{p}$ & $\boldsymbol{X o}$ & $\boldsymbol{X} \boldsymbol{c}$ \\
\hline C1 & 100.00 & 0.00 & 0.00 \\
C2 & 67.00 & 33.00 & 0.00 \\
C3 & 33.00 & 67.00 & 0.00 \\
C4 & 0.00 & 100.00 & 0.00 \\
C5 & 87.33 & 0.00 & 12.67 \\
C6 & 58.52 & 28.81 & 12.67 \\
C7 & 28.81 & 58.52 & 12.67 \\
C8 & 0.00 & 87.33 & 12.67 \\
C9 & 77.52 & 0.00 & 22.48 \\
\hline
\end{tabular}


Table 3. Cont.

\begin{tabular}{cccc}
\hline Samples & $\boldsymbol{X} \boldsymbol{p}$ & $\boldsymbol{X o}$ & $\boldsymbol{X} \boldsymbol{c}$ \\
\hline C10 & 51.94 & 25.58 & 22.48 \\
C11 & 25.58 & 51.94 & 22.48 \\
C12 & 0.00 & 77.52 & 22.48 \\
\hline
\end{tabular}

\subsection{Characterization}

\subsubsection{Mechanical Testing}

Tensile, flexural and impact tests of the hybrid composite were carried out according to ASTM D3039, ASTM D7264 and ASTM D 790-02 respectively. The specimen testing was performed under controlled environmental conditions at $23^{\circ} \mathrm{C}$ and relative humidity at $65 \%$. The tensile test of the specimens of size $(25 \mathrm{~mm} \times 203 \mathrm{~mm})$ was carried out on a universal testing machine (model UMT Z 100 Allroundline, Zwick-Germany). The flexural tests (3-point bending) of specimens with size $(13 \mathrm{~mm} \times 120 \mathrm{~mm})$ were carried out using a thickness to span ratio of 24 . The impact test was conducted on a pendulum impact tester (model HIT5.5P, ZWICK-Germany).

\subsubsection{Environmental Degradation/Weathering Related Properties}

The environmental degradation or the impact of weathering on the hybrid composites for outdoor exposure was tested according to ASTM D2565-99. The test was conducted on xenon arc weather-Odometer (Atlas Ci 4000) in two cycles. In the first cycle of $18 \mathrm{~h}$, the specimen was exposed to light for $102 \mathrm{~min}$, and water was sprayed for $18 \mathrm{~min}$. Black panel temperature was maintained at $40^{\circ} \mathrm{C}$, having a radiant flux of $41.5 \mathrm{~W} \cdot \mathrm{m}^{-2}$ in the range of 300 to $400 \mathrm{~nm}$. In the second cycle, the specimen was exposed in the dark with a relative humidity of $95 \%$ with no water spray for $6 \mathrm{~h}$ at $38^{\circ} \mathrm{C}$ black panel temperature. In order to analyze the impact of weathering, the density of composite samples was measured before and after the weathering condition. Further, the percentage decrease in the total density of composite samples was calculated. Surface images were analyzed in order to visually examine the change in the surface of hybrid composite samples both before and after the weathering conditions. The water absorption behavior of hybrid composites was studied according to ASTM D570. The sample was cut into a circular disk of $5 \mathrm{~cm}$ diameter. Firstly, the specimen samples were dried at $40^{\circ} \mathrm{C}$ for $24 \mathrm{~h}$ in an oven. All the specimens were then cooled at room temperature for $30 \mathrm{~min}$. The conditioned specimens were then immersed in distilled water at $23^{\circ} \mathrm{C}$ for $24 \mathrm{~h}$. Before and after immersion, the specimens were weighed to the nearest value of $0.001 \mathrm{~g}$. The water absorption capacity was calculated by weight difference, and using the following equation.

Water absorption capacity,

$$
\mathrm{w} \%=\left(\frac{\mathrm{w}_{\mathrm{t}}-\mathrm{w}_{0}}{\mathrm{w}_{0}}\right) \times 100
$$

$$
\mathrm{w}_{0}=\text { oven-dry weight, } \mathrm{w}_{\mathrm{t}}=\text { weight of specimen after immersion. }
$$

\subsubsection{Thermal Properties}

The thermal properties (coefficient of linear thermal expansion (CTE) and thermogravimetric analysis TGA) of the hybrid composite were determined as per standard procedures. The effect of temperature on thermal expansion of the specimens was studied according to ASTM E831 of thermal expansion on DIL801L Dilatometer-TA Instrument with the temperature ranging from room temperature to $150^{\circ} \mathrm{C}$. Thermogravimetric analysis (TGA) of the samples was carried out according to ASTM E1131 on NETZSCH TG 209F1 Libra. A $5 \mathrm{mg}$ sample size was used to determine the TGA parameters. Thermogravimetric analysis was carried out under an oxygen environment from room temperature to $600{ }^{\circ} \mathrm{C}$ with a rate of increase of $10^{\circ} \mathrm{C} / \mathrm{min}$. The effect of increasing temperature on the degradation profile was studied and peak degradation temperatures were recorded. 


\section{Results and Discussion}

In this research, Mixture Design Analysis was used to forecast corresponding responses, i.e., mechanical properties (tensile strength, flexural strength, impact strength), environmental effects (loss of density after exposure to weathering chamber and water absorption) as well as coefficient of thermal expansion by the input of component proportion, e.g., polyester waste fibers $(X p)$, olive root fibers $\left(X_{o}\right)$ and coir pith filler $\left(X_{c}\right)$. The effect of polyester waste fibers and olive root fiber as reinforcement and coir pith as incorporating filler into polyester resin on its mechanical, environmental, and thermal properties are evaluated. The responses are the functions of properties of different components in the mixture. The obtained experimental results for mechanical properties, environmental degradation properties, and thermal properties are shown in Table 4 . At $95 \%(\alpha=0.05)$ confidence level ANOVA tables were generated to determine the results. According to the $p$-value (probability value), the significance level of each term was determined. If the $p$-value will be more than $95 \%(\alpha \leq 0.05)$ each input component will have a significant effect on response and in case if probability value will be less than $95 \%(\alpha \geq 0.05)$ then the influence could not be considered significant and should be rejected from the final analysis because they do not have a significant effect. Moreover, the null hypothesis will be eliminated.

Table 4. Properties of samples investigated.

\begin{tabular}{|c|c|c|c|c|c|c|c|c|c|}
\hline $\begin{array}{c}\text { Sample } \\
\text { Code }\end{array}$ & $\begin{array}{c}\text { Tensile } \\
\text { Strength } \\
\text { (MPa) }\end{array}$ & $\begin{array}{c}\text { Tensile } \\
\text { Moduli } \\
\text { (GPa) }\end{array}$ & $\begin{array}{c}\text { Flexural } \\
\text { Strength } \\
(\mathrm{MPa})\end{array}$ & $\begin{array}{c}\text { Flexural } \\
\text { Moduli } \\
\text { (GPa) }\end{array}$ & $\begin{array}{c}\text { Impact } \\
\text { Strength } \\
\left(\mathrm{KJ} / \mathrm{m}^{2}\right)\end{array}$ & $\begin{array}{c}\text { Water } \\
\text { Absorbtion } \\
(\%)\end{array}$ & $\begin{array}{c}\text { Initial } \\
\text { Density } \\
\left(\mathrm{g} / \mathrm{cm}^{3}\right)\end{array}$ & $\begin{array}{c}\text { Weathered } \\
\text { Density } \\
\left(\mathrm{g} / \mathrm{cm}^{3}\right)\end{array}$ & $\begin{array}{c}\text { CTE } \\
\left(10^{-6 / K}\right)\end{array}$ \\
\hline $\mathrm{C} 1$ & 16.93 & 3.25 & 36.31 & 1.14 & 6.6886 & 3.24 & 0.984 & 0.968 & -16.56 \\
\hline $\mathrm{C} 2$ & 20.74 & 3.71 & 48.32 & 1.61 & 5.9985 & 4.13 & 0.964 & 0.942 & -11.86 \\
\hline $\mathrm{C} 3$ & 16.58 & 3.97 & 35.83 & 1.84 & 4.5893 & 4.94 & 1.182 & 1.146 & -9.1 \\
\hline $\mathrm{C} 4$ & 15.46 & 5.21 & 34.84 & 2.02 & 4.0293 & 7.64 & 1.156 & 1.111 & -8.14 \\
\hline C5 & 25.22 & 2.85 & 79.02 & 2.12 & 7.0858 & 4.41 & 1.199 & 1.15 & -9.86 \\
\hline C6 & 27.02 & 3.29 & 86.90 & 4.11 & 6.8967 & 5.78 & 1.135 & 1.083 & -8.25 \\
\hline C7 & 24.64 & 3.80 & 73.42 & 4.46 & 6.2576 & 6.33 & 0.968 & 0.908 & -6.37 \\
\hline $\mathrm{C} 8$ & 22.32 & 3.86 & 55.22 & 5.44 & 5.6868 & 8.92 & 0.983 & 0.896 & -4.72 \\
\hline C9 & 17.09 & 2.31 & 34.74 & 1.25 & 9.1548 & 6.17 & 1.162 & 1.051 & 11.64 \\
\hline C10 & 19.53 & 2.62 & 44.56 & 1.93 & 9.0445 & 7.03 & 1.009 & 0.887 & 10.72 \\
\hline C11 & 16.76 & 2.81 & 33.22 & 3.35 & 8.5619 & 9.48 & 1.087 & 0.946 & 8.76 \\
\hline C12 & 14.86 & 3.23 & 31.90 & 3.87 & 7.3260 & 10.9 & 1.132 & 0.964 & 7.31 \\
\hline G & 88.83 & 10.66 & 158.66 & 4.99 & 64.61 & 2.58 & 1.148 & 1.136 & 3.4 \\
\hline
\end{tabular}

G-Fiber glass commercial sample.

The experimental results reflect the influence of fiber properties, fiber volume fraction and interfacial strength on the mechanical, thermal and environmental properties of the hybrid composites. The constituents of the hybrid composites are PET fibers, olive root fibers, coir pith micro-particles and polyester resin. The individual component properties and their corresponding proportion play a vital role in deciding the performance of the hybrid composites. A blend proportion of 67:33 for PET:Olive root fibers results in the highest tensile strength in the composite samples. The PET fibers are stronger than olive root fibers and thus as the olive root fiber proportion increases, the tensile strength decreases. The addition of $12.67 \%$ coir pith micro-particles, leads to an increase in tensile strength. As the proportion of coir pith micro-particles further increases, there is a decrease in the overall fiber component in order to maintain the total content of reinforcement constant. Based on the Halpin-Tsai model, the tensile strength decreases [32,33]. With respect to the tensile modulus of the hybrid composite samples, they are inversely proportional to the tensile deformation of individual components. The olive root fibers are less extensible as compared to PET fibers. Thus, the increasing proportion of olive root fibers, leads to an increase in the tensile modulus. An increase in coir pith particles in the mixture results in a decrease in fibrous components. Therefore, a decrease in tensile modulus is observed. 
The flexural properties are very much similar to tensile properties. The bending deformation in a composite sheet, results in tensile deformation on the outer surface and longitudinal compression on the inner surface. The observed behavior is following the Halpin-Tsai model equations [32,33]. A blend proportion of 58.52\% (PET), 28.81\% (Olive root fiber) and $12.67 \%$ (Coir pith particles) results in the highest tensile and flexural strength.

Impact performance is a multiaxial deformation, unlike tensile or bending. It depends on the mechanical performance of components as well as their interaction in the radial and thickness direction. PET fibers being stronger than other reinforcing components in the mixture, are very much dominant in deciding the impact energy absorption. Further, a highly extensible fiber enables better absorption of the momentum of impact. Thus, the higher proportion of PET, results in higher impact strength. The addition of coir pith microparticles results in an increase in impact strength, despite the corresponding decrease in the fibrous component. This is quite different from the observations regarding tensile and bending performance. This behavior can be attributed to the interfacial bonds provided by the micro-particles with the resin component and thus improvement in the multiaxial resistance to impact. This behavior is not so prominent under uniaxial deformations, e.g., tensile or bending.

Water absorption is dependent on the hygroscopic component proportion. Both olive root fibers, as well as coir pith, are water-absorbing components, unlike PET fibers. Thus, a decreasing proportion of PET fibers and an increasing proportion of olive root fiber and coir pith particles result in an increase in water absorption capacity. In comparison to the other two components, the coir pith particles are more porous and thus are able to absorb a higher amount of liquid water. An increasing proportion of coir pith micro-particles results in increase in water absorption capacity, The Halpin-Tsai model is validated by these observations [33].

Due to the weathering treatment, there is a degradation of some components which results in loss of weight and an increase in the volume of the composites. The decrease in density is dependent on the proportion of degradable components in the mixture. Since olive root and coir pith are biodegradable components, a higher proportion of such materials leads to more decrease in density.

The coefficient of thermal expansion (CTE) is governed by several models, e.g., the Voigt model [34] and the Reuss model [35]. The overall CTE of hybrid composites is governed by the \% fraction, elastic modulus and CTE of individual components. As PET is a thermoplastic fiber, it might deform and melt during heating and thus causing shrinkage of the composite. As the portion of PET fibers is decreased, there is a decrease in the level of thermal deformation. The increase in cellulosic components decreases the level of thermal shrinkage or expansion. Thus, the thermal stability of hybrid composites is improved. The addition of $12.67 \%$ coir pith particles reduces the thermal shrinkage in hybrid composites. However, with an increasing proportion of coir particles and a corresponding decrease in fibrous components, there is a significant increase in the thermal expansion coefficient. Unlike fibrous reinforcements, coir pith micro-particles are discontinuous elements. They might not restrict the thermal deformations in the resin phase as efficiently as the fibers. This might be the reason behind higher CTE in coir particle-rich samples. It is consistently observed that decreasing proportion of PET fibers and increasing proportion of olive root fibers results in a decrease in thermal expansion coefficient. Such observations are also supported by reported literature from other researchers [34,36].

\subsection{Scanning Electron Microscopy (SEM) of Composite Samples}

The hybrid composite samples were tested for the mechanical, thermal and environmental/weathering properties. SEM images of tensile-tested hybrid composite samples are shown in Figure 3. 


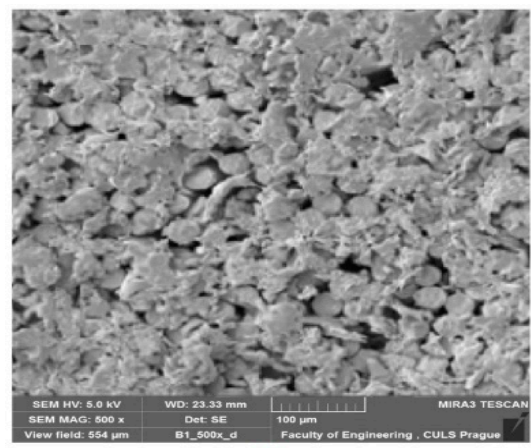

C1

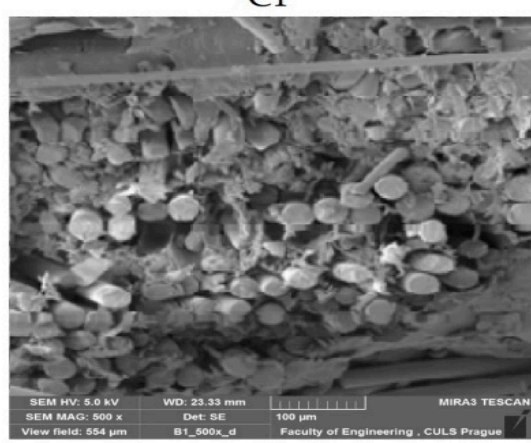

$\mathrm{C} 2$

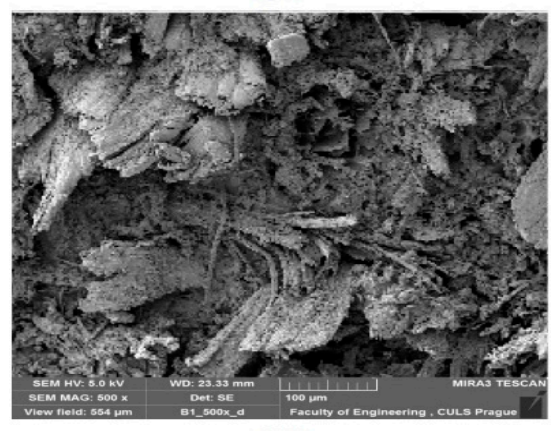

C3

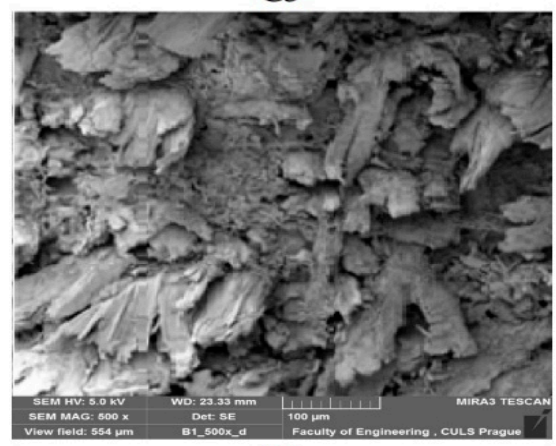

$\mathrm{C} 4$

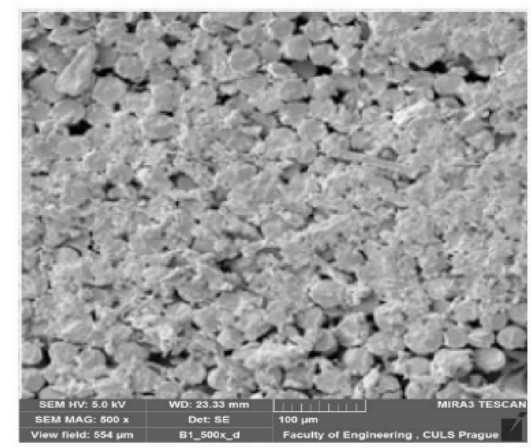

C5

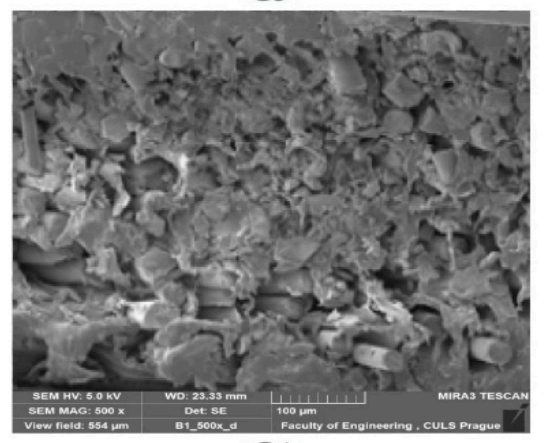

C6

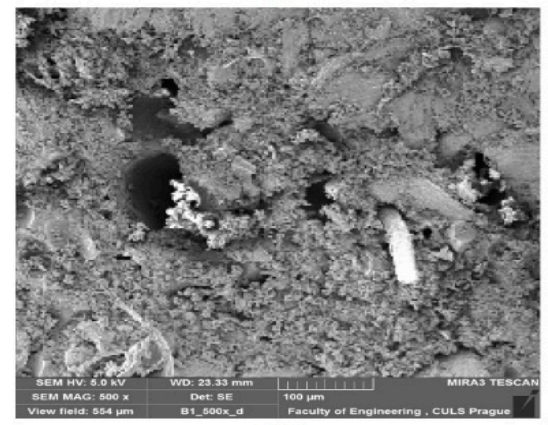

C7

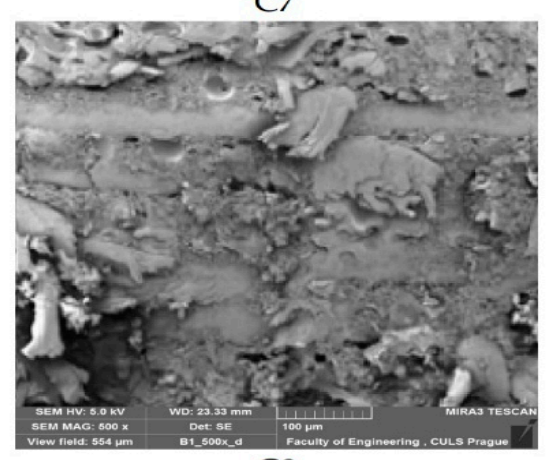

C8

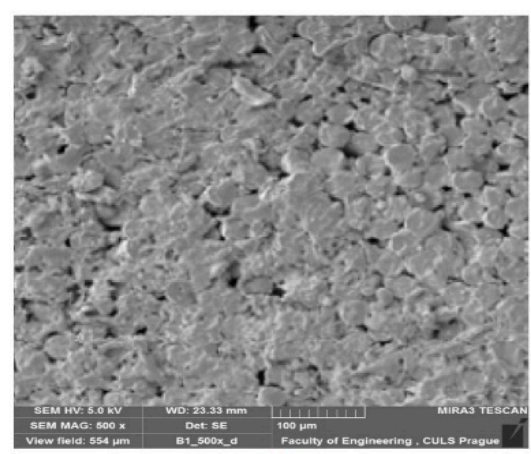

C9

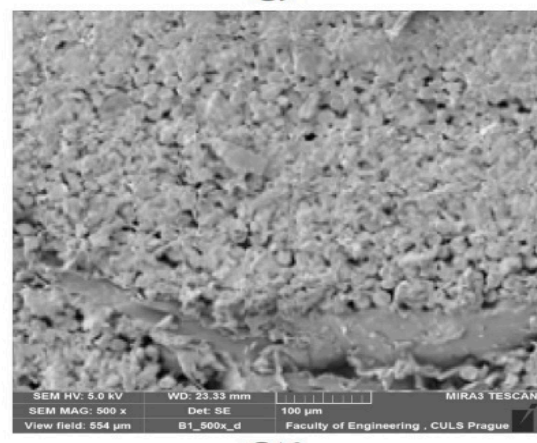

$\mathrm{C} 10$

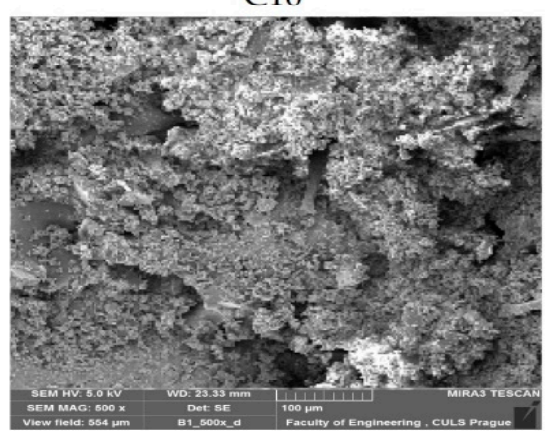

C11

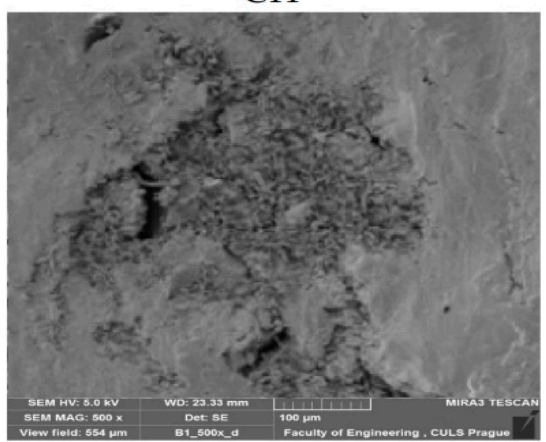

C12

Figure 3. SEM images of tensile tested hybrid composite samples (C1-C12 as in Table 3).

It is visible from the SEM images that the hybrid composites and composites are free from any major defects. The fibrous reinforcement is uniformly impregnated by the matrix phase. When the composite samples contain only one type of fiber, i.e., pure polyester or pure olive root fiber, there is more uniformity. While mixing the polyester and olive root fibers, there are a few minor voids in between the dissimilar fibers. This might be because the diameter, as well as surface morphology of polyester and olive root fibers, is quite different from each other. The pure polyester fiber-based composites show much better impregnation with unsaturated polyester resin. In this case, both the reinforcing fibers as well as resin are based on similar polymers and thus result in better impregnation. 
On the other hand, olive root fibers are mainly composed of cellulose. Therefore, there are a few minor voids at the fiber-matrix interface. Such voids however are compensated by the hybridization effect in several samples. The addition of coir pith-based cellulosic micro-particles helps in a much better interface with the resin. The uniformly dispersed micro-particles fill all the minor voids around the fibrous phase. Such effect is visible in all the pure as well as hybrid composite samples prepared during this investigation.

\subsection{Modeling and Statistical Analysis of Experimental Data}

Significance models were chosen for all responses using linear, quadratic and special cubic functions of Scheffe's polynomial equations as given below $[37,38]$.

$$
\begin{gathered}
\mathrm{Y}=b 1 \mathrm{X} 1+b 2 \mathrm{X} 2+b 3 \mathrm{X} 3 \\
\mathrm{Y}=b 1 \mathrm{X} 1+b 2 \mathrm{X} 2+b 3 \mathrm{X} 3+b 12 X 1 X 2+b 13 \mathrm{X} 1 \mathrm{X} 3+b 23 \mathrm{X} 2 \mathrm{X} 3 \\
\mathrm{Y}=b 1 \mathrm{X} 1+b 2 \mathrm{X} 2+b 3 \mathrm{X} 3+b 12 \mathrm{X} 1 \mathrm{X} 2+b 13 \mathrm{X} 1 \mathrm{X} 3+b 23 \mathrm{X} 2 \mathrm{X} 3+b 123 \mathrm{X} 1 \mathrm{X} 2 \mathrm{X} 3
\end{gathered}
$$

where $b 1, b 2, b 3, b 12, b 13, b 23$ and $b 123$ are the coefficients of equations that are determined according to the model. $X 1, X 2, X 3, X 1 X 2, X 1 X 3, X 2 X 3$ and $X 1 X 2 X 3$ are the component proportions in the mixture and $\mathrm{Y}$ is the dependent variable (responses). However, for all the responses the quadratic model was chosen to be fit for tensile strength, flexural strength, impact energy, water absorption, thermal expansion and the loss of density. Hence, the quadratic models for three-component mixture design take the final form as given below [39]:

$$
\eta=\beta 1 \times 1+\beta 2 \times 2+\beta 3 \times 3+\beta 12 \times 1 \times 2+\beta 13 \times 1 \times 3+\beta 23 \times 2 \times 3
$$

where,

$\eta=$ Response (mechanical, environmental or thermal)

$\beta i^{\prime} s=$ Coefficients of equation, $X i^{\prime} s=$ Component proportion in mixture.

\subsection{Regression Coefficient and Quadratic Model for All Mechanical, Environmental and Thermal Responses}

Statistical summaries of model responses and regression coefficients are determined using Minitab software version 19.1.1. The regression equations corresponding to the best fit models were selected for the estimation of the corresponding mechanical property. Regression coefficients with the probabilities are shown in Tables 5-7 for mechanical, environmental and thermal responses respectively. Moreover, quadratic equations were determined from their Regression coefficients as shown below.

$$
\begin{aligned}
& \eta=17.35 X p+19.21 X o-367.4 X c+8.53 X p X o+470.4 X o X c \\
& \eta=33.75 X p+36.81 X o-1140 X c+1854 X p X c+1919 X o X c \\
& \eta=6.532 \mathrm{X} p+3.905 \mathrm{X} o-59.8 \mathrm{X} c-53.4 \mathrm{X} p \mathrm{Xc}-50.2 \mathrm{XoXc} \\
& \eta=3.35 X p+7.41 X o+54.3 X c-3.53 X p X o-49.21 X p X c \\
& \eta=1.933 \mathrm{X} p+11.916 \mathrm{Xo}+18.8 \mathrm{X} c-8.89 \mathrm{X} p \mathrm{Xo} \\
& \eta=-12.48 X p-12.08 X o+970 X c-1123 X p X c-1096 X o X c
\end{aligned}
$$

The terms having not significant probability were eliminated from the final equations. Regression Equations (6)-(8) are for tensile strength, flexural strength, and impact strength respectively. Equations (9)-(11) are used for the estimation of water absorption, loss of density due to weathering, and coefficient of thermal expansion respectively. 
Table 5. Analysis of Variance for Tensile strength (MPa), Flexural strength (MPa), and Impact Strength $\left(\mathrm{KJ} / \mathrm{m}^{2}\right)$.

\begin{tabular}{|c|c|c|c|c|c|c|}
\hline Source & DF & Seq SS & Adj SS & Adj MS & F-Value & $p$-Value \\
\hline Tensile strength Regression & 5 & 130.971 & 130.971 & 26.194 & 16.48 & 0.002 \\
\hline Linear & 2 & 8.081 & 101.697 & 50.848 & 32.00 & 0.002 \\
\hline Quadratic & 3 & 122.889 & 122.889 & 40.963 & 25.78 & 0.001 \\
\hline$X p^{*} X o$ & 1 & 6.537 & 6.913 & 6.913 & 4.35 & 0.082 \\
\hline$X p^{*} X c$ & 1 & 26.506 & 105.793 & 105.793 & 66.57 & 0.000 \\
\hline$X o^{*} X c$ & 1 & 89.846 & 89.846 & 89.846 & 56.54 & 0.000 \\
\hline Residual Error & 6 & 9.535 & 9.535 & 1.589 & & \\
\hline Total & 11 & 140.506 & & & & \\
\hline Flexural strength Regression & 5 & 2099.31 & 2099.3 & 419.86 & 5.31 & 0.033 \\
\hline Linear & 2 & 282.76 & 1490.1 & 745.05 & 9.43 & 0.024 \\
\hline Quadratic & 3 & 1816.55 & 1816.5 & 605.52 & 7.66 & 0.018 \\
\hline$X p^{*} X_{0}$ & 1 & 312.47 & 322.4 & 322.42 & 4.08 & 0.090 \\
\hline$X p^{*} X c$ & 1 & 9.61 & 1395.8 & 1395.85 & 17.66 & 0.006 \\
\hline$X o^{*} X c$ & 1 & 1494.47 & 1494.5 & 1494.47 & 18.91 & 0.005 \\
\hline Residual Error & 6 & 474.13 & 474.1 & 79.02 & & \\
\hline Total & 11 & 2573.44 & & & & \\
\hline Impact strength Regression & 5 & 28.1916 & 28.1916 & 5.63833 & 55.56 & 0.000 \\
\hline Linear & 2 & 26.8809 & 6.2415 & 3.12073 & 30.75 & 0.081 \\
\hline Quadratic & 3 & 1.3107 & 1.3107 & 0.43692 & 4.31 & 0.061 \\
\hline$X p^{*} X o$ & 1 & 0.0949 & 0.0902 & 0.09024 & 0.89 & 0.382 \\
\hline$X p^{*} X c$ & 1 & 0.1915 & 1.1597 & 1.15968 & 11.43 & 0.015 \\
\hline$X o^{*} X c$ & 1 & 1.0243 & 1.0243 & 1.02428 & 10.09 & 0.019 \\
\hline Residual Error & 6 & 0.6089 & 0.6089 & 0.10148 & & \\
\hline Total & 11 & 28.8005 & & & & \\
\hline
\end{tabular}

Table 6. Analysis of Variance (component proportions) for water absorption (\%) and decrease in density (\%).

\begin{tabular}{|c|c|c|c|c|c|c|c|}
\hline & Source & DF & Seq SS & Adj SS & Adj MS & F-Value & $p$-Value \\
\hline \multirow[t]{8}{*}{ Water absorption (\%) } & Regression & 5 & 58.1772 & 58.1772 & 11.6354 & 62.11 & 0.000 \\
\hline & Linear & 2 & 55.2076 & 11.7230 & 5.8615 & 31.29 & 0.081 \\
\hline & Quadratic & 3 & 2.9696 & 2.9696 & 0.9899 & 5.28 & 0.040 \\
\hline & $X p^{*} X o$ & 1 & 1.2039 & 1.2183 & 1.2183 & 6.50 & 0.043 \\
\hline & $X p^{*} X c$ & 1 & 1.1209 & 0.9798 & 0.9798 & 5.23 & 0.062 \\
\hline & $X o^{*} X c$ & 1 & 0.6448 & 0.6448 & 0.6448 & 3.44 & 0.113 \\
\hline & Residual Error & 6 & 1.1241 & 1.1241 & 0.1873 & & \\
\hline & Total & 11 & 59.3013 & & & & \\
\hline \multirow[t]{8}{*}{ Loss in density $(\%)$} & Regression & 5 & 222.356 & 222.356 & 44.4711 & 110.49 & 0.000 \\
\hline & Linear & 2 & 208.552 & 61.435 & 30.7177 & 76.32 & 0.014 \\
\hline & Quadratic & 3 & 13.803 & 13.803 & 4.6012 & 11.43 & 0.007 \\
\hline & $X p^{*} X o$ & 1 & 7.493 & 7.497 & 7.4972 & 18.63 & 0.005 \\
\hline & $X p^{*} X c$ & 1 & 6.295 & 0.126 & 0.1259 & 0.31 & 0.596 \\
\hline & $X o^{*} X c$ & 1 & 0.016 & 0.016 & 0.0157 & 0.04 & 0.850 \\
\hline & Residual Error & 6 & 2.415 & 2.415 & 0.4025 & & \\
\hline & Total & 11 & 224.770 & & & & \\
\hline
\end{tabular}

Table 7. Analysis of variance for the coefficient of thermal expansion.

\begin{tabular}{cccccccc}
\hline & Source & DF & Seq SS & Adj SS & Adj MS & F-Value & $p$-Value \\
\hline Thermal expansion & Regression & 5 & 2199.86 & 2199.9 & 439.97 & 5.57 & 0.030 \\
& Linear & 2 & 1573.42 & 645.9 & 322.96 & 4.09 & 0.176 \\
& Quadratic & 3 & 626.43 & 626.4 & 208.81 & 2.64 & 0.144 \\
& $X p^{*} X o$ & 1 & 113.86 & 117.4 & 117.39 & 1.49 & 0.269 \\
$X p^{*} X c$ & 1 & 24.87 & 512.1 & 512.10 & 6.48 & 0.044 \\
& $X o^{*} X c$ & 1 & 487.71 & 487.7 & 487.71 & 6.17 & 0.048 \\
& Residual Error & 6 & 474.23 & 474.2 & 79.04 & & \\
& Total & 11 & 2674.08 & & & & \\
& & & & & \\
& &
\end{tabular}




\subsection{Analysis of Variance for Mechanical Responses}

ANOVA Table 5 shows the analysis of all mechanical responses.

For the tensile strength (MPa) response, the quadratic model is well fitted with a probability $p>99 \%$. Two-component interactions, e.g., $\mathrm{X} p^{*} \mathrm{Xo}, \mathrm{X} p^{*} \mathrm{Xc}$ and $\mathrm{Xo}{ }^{*} \mathrm{Xc}$ have probability of $p=91 \%, p>99 \%$ and $p>99 \%$ respectively. The two-component interactions of $X p^{*} X c$ and $X o^{*} X c$ significantly affect the tensile strength of hybrid composites with a probability of $p>99 \%$. Still, $X p^{*} X o$ component interaction has an insignificant effect with the probability of $p=91 \%(p<95 \%)$. The quadratic model also fits the flexural strength (MPa) with a $p>98 \%$ as shown in two-component proportion interaction. Both $X p^{*} X c$ and $X o^{*} X c$ affect the response significantly with $p>99 \%$ respectively. Therefore, both have the highest degree of influence on flexural strength (MPa). However, $X p^{*} X o$ component interaction has not been significantly influential due to lower probability $(p=91 \%)$. Analysis of variance shows that the quadratic model is also well-fitted for the impact strength of the hybrid composites because it indicates a significant probability of $p=94 \%$. Two-component proportion interaction of $X p^{*} X o$ has an insignificant effect on impact response with the probability of $p=62 \%$. However, other two-component interactions $X p^{*} X c$ and $X o^{*} X c$ have a strong effect on impact response with the probability of $p>98 \%$ respectively. Therefore, the quadratic model is considered a good fit for the impact strength of hybrid composites.

\subsubsection{Normal Probability Plots of Residuals for Mechanical Responses}

Normal probability plots of the residuals determine whether the collected data fit the selected models by the plot point distribution and by comparing the distribution of different samples. If the plotted point distribution is close to the fitted line slope, then the model distribution fits the collected data. For all mechanical properties the residual normal probability plots as shown in Figure 4.

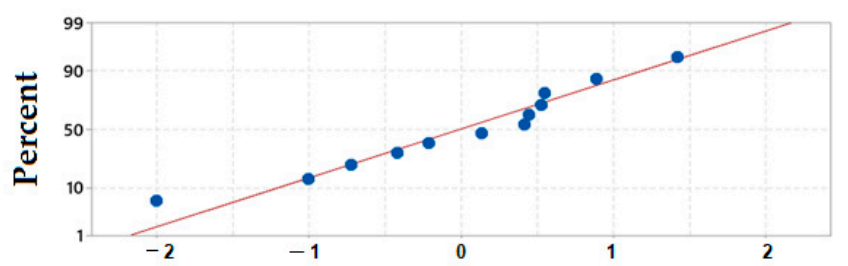

Residual of tensile strength

(a)

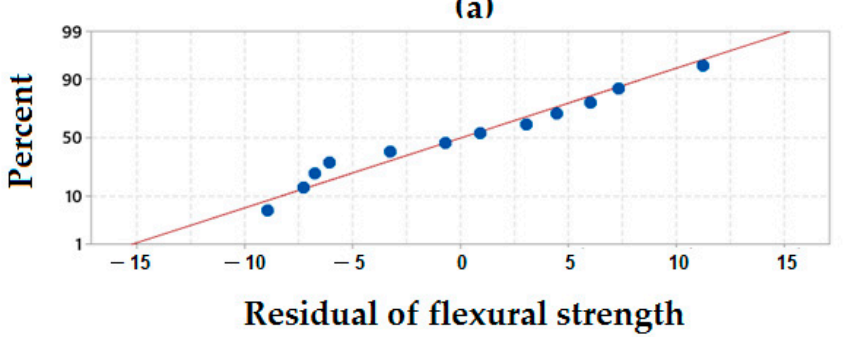

(b)

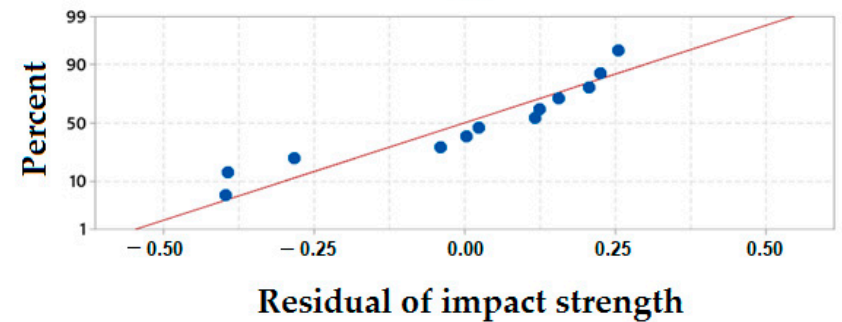

(c)

Figure 4. Normal probability plots of residuals (a) tensile strength, (b) flexural strength and (c) impact strength. 
Figure $4 \mathrm{a}, \mathrm{b}$ show the scatter plots for tensile strength and flexural strength respectively. The plots show that the majority of the points are distributed close to the slope (line) and only a few points are distributed far from the line. In the case of flexural strength, the normal probability plot indicates that approximately all the points are very close to the distribution slope as compared to the plot of tensile strength. Figure $4 \mathrm{c}$ shows the normal probability plot of impact strength. It can be noted that the points are somewhat clustered with a relatively lower probability of distribution on the slope line. In general, it can be concluded that all the mechanical responses are quite close to the slope of normal distribution.

\subsubsection{Response Trace Plots for Mechanical Properties}

Responses trace plots are also known as component effect plots. These plots help to analyze the effect of each proportion of individual components in a mixture on a selected response. The effect of varying component proportions along the imaginary line connecting the reference mixture on the vertex is shown by response trace curves. For the mechanical properties, response trace plots are shown in Figure 5a-c.

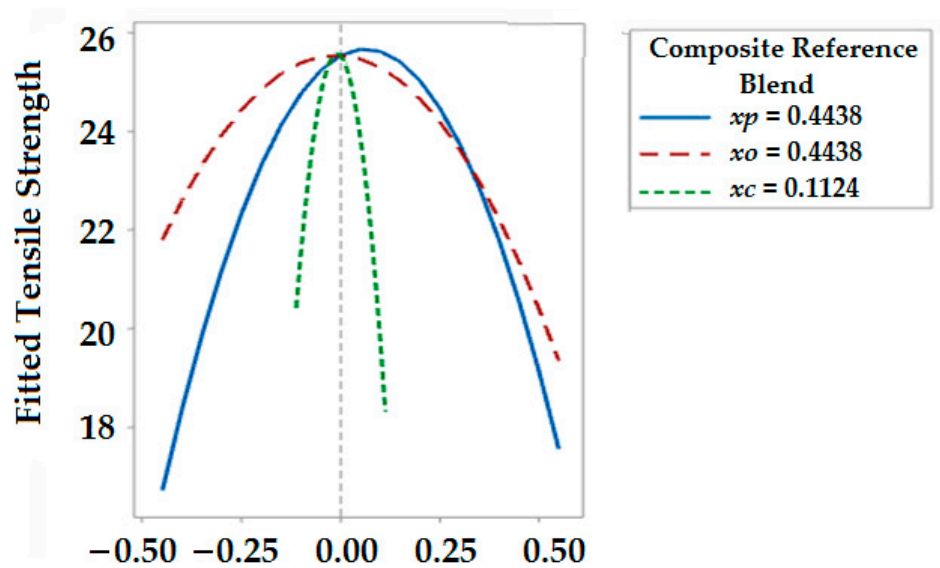

Deviation from reference blend proportion

(a)

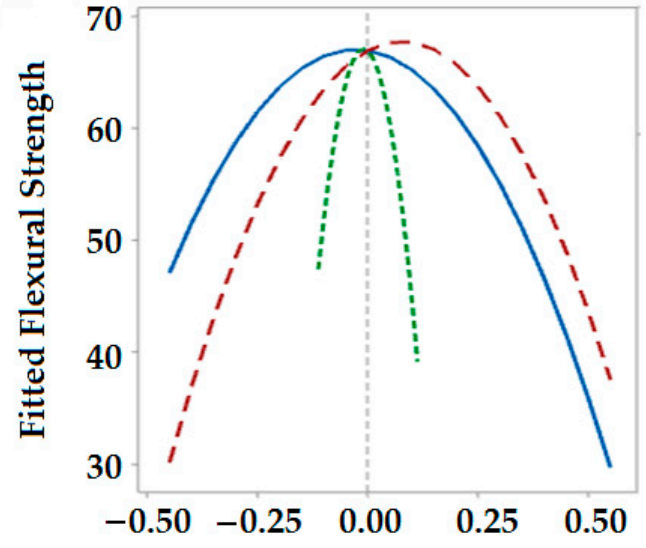

Deviation from reference blend proportion

(b)

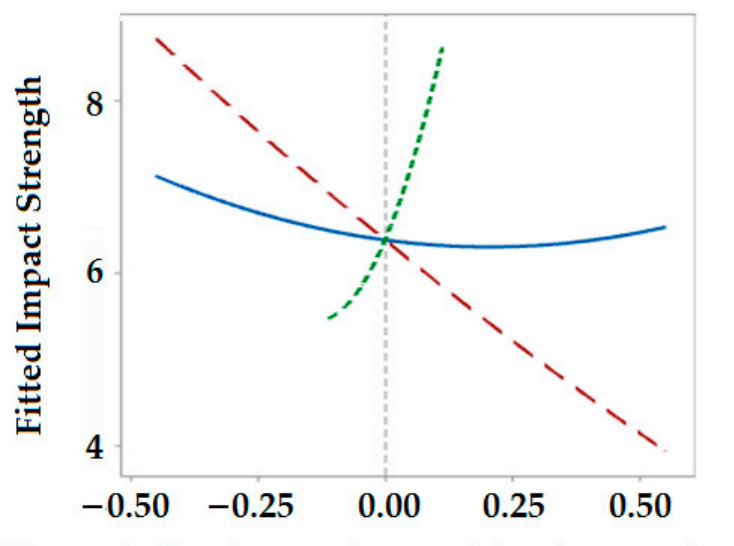

Deviation from reference blend proportion

(c)

Figure 5. Response trace plots for (a) Tensile strength (MPa), (b) Flexural strength (MPa), (c) Impact strength $\left(\mathrm{KJ} / \mathrm{m}^{2}\right)$.

As can be seen in Figure 5a, there is an increase in tensile strength to a magnitude of about $27 \mathrm{MPa}$ with an increasing proportion of polyester waste fibers $(\mathrm{Xp})$. The proportion of olive root fibers $(\mathrm{Xo})$ is maintained at an optimum level before the tensile strength starts to decrease. Such findings are in accordance with the mechanical properties of polyester 
and olive root fibers. The polyester fibers are stronger than the olive root fibers and thus dominate their influence on the tensile strength of the composites. The addition of excess fibers beyond a certain limit leads to improper impregnation and a decrease in strength. It is also visible that the proportion of coir pith micro-particles $(X c)$ enhances the tensile strength to an optimum extent and further addition of coir pith decreases the tensile strength. micro-particles provide a very high interfacial area for bonding and thus enhance mechanical properties in a composite system. The behavior is reflecting the findings in literature based on Halpin-Tsai equations [32,33].

Figure $5 \mathrm{~b}$ shows that flexural strength approaches a maximum magnitude of $78 \mathrm{MPa}$ with an increasing proportion of olive root fibers and a decreasing proportion of polyester fiber in the mixture. The flexural strength is dominated by the olive root fibers as they are coarser and show higher stiffness as compared to polyester waste fibers. Moreover, the flexural strength increases to an optimum level with an increase in the proportion of micro-fillers, and subsequently shows a decreasing trend.

The response trace plot in Figure $5 c$ indicates that the impact strength of hybrid composites linearly decreases with an increased proportion of olive root fibers. Polyester fibers are stronger and have a higher shock-absorbing capacity. Moreover, the coir pith micro-particles have a similar effect on the impact properties of hybrid composites. The micro-fillers improve overall bonding with the matrix and thus enhance the bulk mechanical properties, e.g., absorption of impact stresses. The component ratio is observed to have a synergistic effect on the mechanical properties investigated in this research.

\subsubsection{Contour Plots for Mechanical Responses}

A contour plot is a two-dimensional plot that indicates the effect of varying combinations of mixture components on the magnitude of response. The contour plot shows differently colored regions corresponding to the magnitude of responses. The higher magnitude of response is shown by the highlighted darker-colored regions compared to the lighter-colored regions. The contour plot can calculate the proportions of the components in the mixture and indicate the magnitude of different responses for corresponding color regions. The contour plots for mechanical properties are shown in Figure 6.
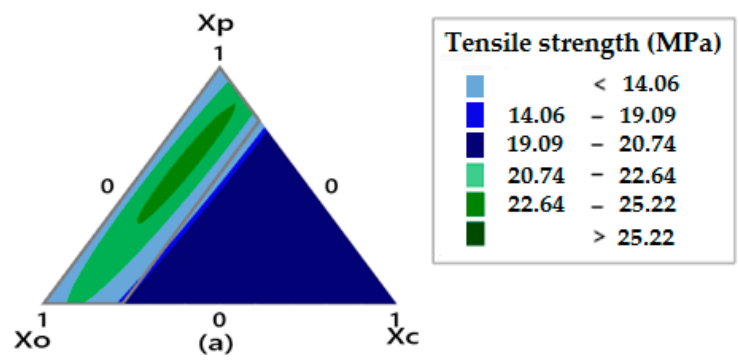

(a)
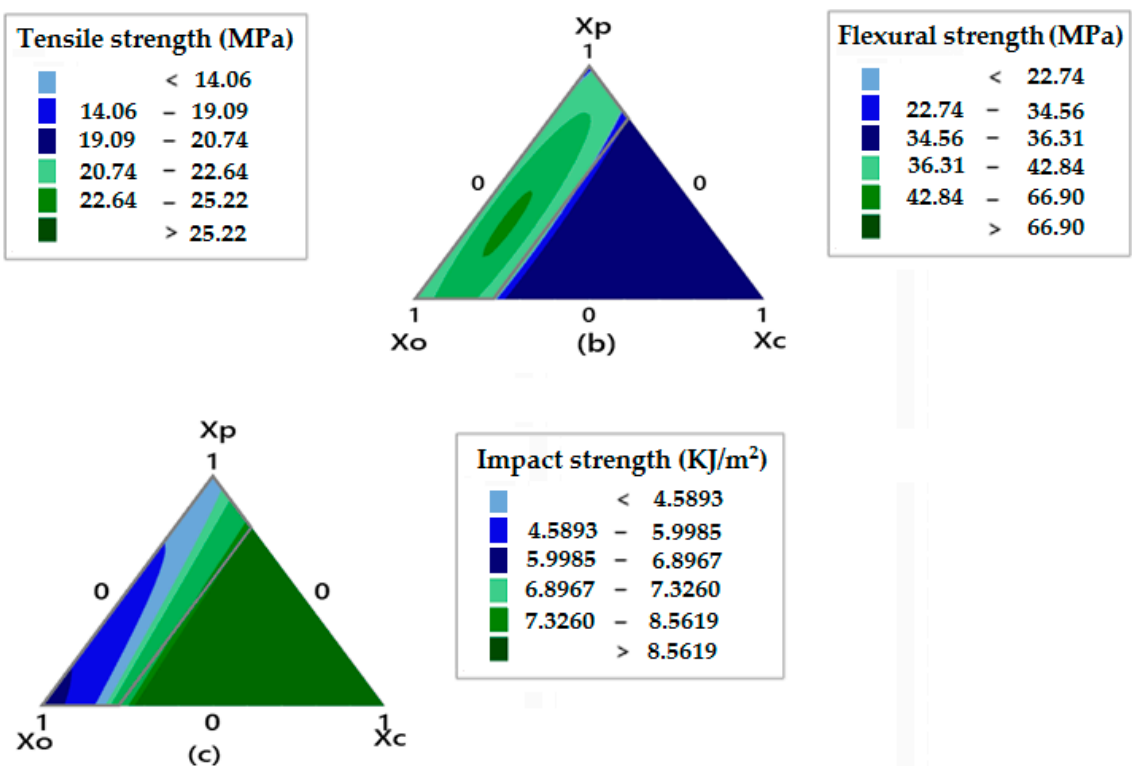

(b)

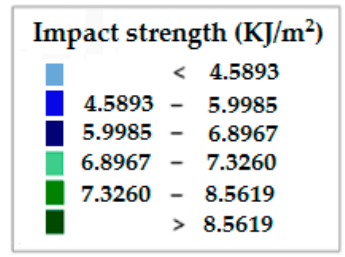

(c)

Figure 6. Contour plots for (a) Tensile strength, (b) Flexural strength, (c) Impact strength.

The contour plot shown in Figure 6a indicates the highest value for tensile strength (higher than $27.02 \mathrm{MPa}$ ) in the darker green region which is at the edge of $X p$ (polyester waste fiber) and Xo (olive root fibers). Moving along the contour plot, the highest value for 
the tensile strength response was $27.02 \mathrm{MPa}$, as shown in Table 4 for sample C6 ( $\mathrm{X} p=58.5$, $X o=28.81, X c=12.67)$. The minimum value for the tensile strength was obtained for the sample C12 (Xp =0.00, Xo =77.72, Xc = 22.48) as seen in Table 4. The contour plot of Figure $6 \mathrm{~b}$ shows the maximum flexural strength which is indicated by the darker green region just like the tensile response plot on the edges of Xo (olive root fiber) and Xp (polyester waste fiber) with optimum content of Xc (coir pith micro-particles). Figure $6 c$ indicates a bigger region of darker green shade which implies that the impact strength is substantially affected by a combination of polyester and olive root fiber proportions. Significant improvement of impact strength can be achieved by increasing the proportion of polyester fibers and coir pith micro-particle content. The results are in agreement with the experimental findings. The trends are similar to theoretical calculation of mechanical properties as reported by other researchers based on Halpin-Tsai models [32,33].

As reported in the literature, remarkable enhancement in mechanical properties was observed in hybrid composites from date palm leaf incorporated recycled poly (ethylene terephthalate) developed by injection molding. Impact strength increased with higher loading of fiber. In addition, tensile strength and flexural strength were enhanced by adding a higher proportion of fiber when compared to the neat matrix. Recycle PET combined with date palm leaf could be a good alternative to obtain eco-friendly products [40]. Hybrid composites fabricated by using wood flour, coir pith powder and corn cob with different ratios in PVC, significantly improved tensile strength, flexural strength and energy absorption properties. The incorporation of coir pith and corn cob reduces voids and cavities in the hybrid composite resulting in the improvement of mechanical properties [41].

\subsection{Analysis of Variance for Weathering Related Properties}

ANOVA Table 6 shows the analysis of variance for water absorption response and loss of density after weathering treatment.

It reveals that the quadratic model is a suitable model for the water absorption behavior of hybrid composites since it predicts the response with a probability value of $p=96 \%$. Two-component interactions, e.g., $X p^{*} X o, X p^{*} X c$ and $X o^{*} X c$ have probability of $p=96 \%, p=94 \%$ and $p=89 \%$ respectively. Both $X p^{*} X o, X p^{*} X c$ affect the water absorption properties of composites in a significant manner. The interaction, $\mathrm{Xo} o^{*} \mathrm{Xc}$ component is insignificant due to its poor probability of $p=89 \%$. This means that the water absorption is critically dependent on the proportion of polyester fibers and olive root fibers. Since the proportion of coir pith micro-particles is relatively smaller, it has an insignificant effect on the overall water absorption capacity.

Variance analysis (Table 6), for the percentage decrease in density, indicates that the quadratic model is a significant predictive model with a probability value of $p>99 \%$. The two-component interactions of $X p^{*} X o, X p^{*} X c$ and $X o^{*} X c$ have probability value of $p>99 \%, p=40 \%$ and $p=15 \%$ respectively. These observations indicate that the loss of density is mainly governed by the proportions of polyester and olive root fibers in the hybrid composite. The coir pith micro-particles have an insignificant influence on the loss of density due to their lower proportion.

\subsubsection{Normal Probability Plots of Residuals for Environmental/Weathering Related Properties}

The normal probability plots of residuals for environmental properties are shown in Figure 7. The normal probability plot in Figure 7a shows that the points are very close to the slope line. This validates the normal distribution of water absorption behavior observed in hybrid composites. Additionally, from Figure $7 \mathrm{~b}$, it can be observed that all the fitted points are closer to the distribution slope in case of loss in the density of the composite samples after weathering treatment. This also confirms a normal distribution of the data obtained through the weathering experiment. 


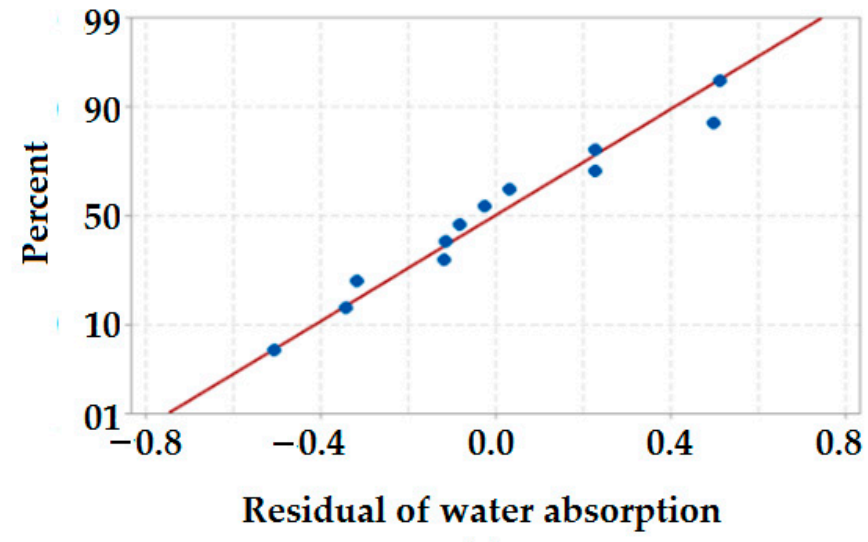

(a)

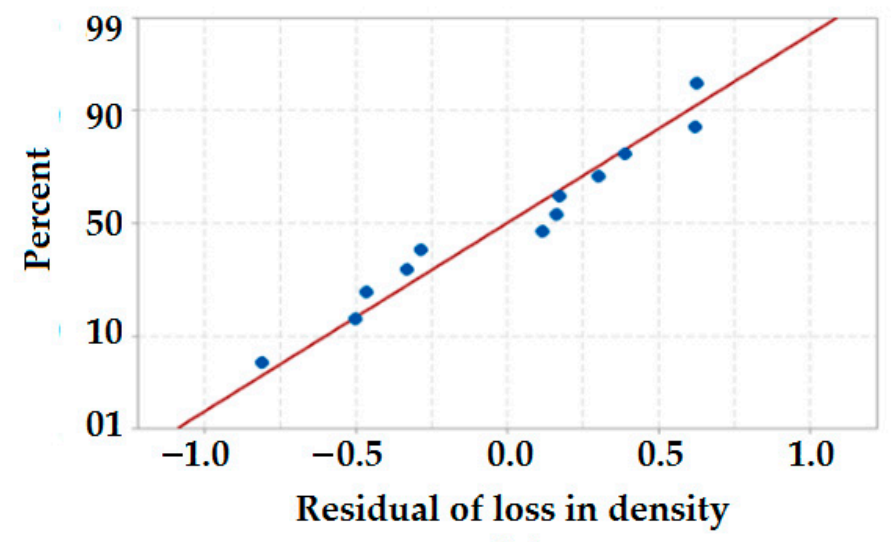

(b)

Figure 7. Normal probability plots of residuals for (a) water absorption (\%), (b) density loss percentage.

\subsubsection{Response Trace Plot for Environmental Properties}

The response trace plot for the water absorption properties of hybrid composites is shown in Figure 8a. It indicates that with the increase in the proportion of polyester fiber, water absorption decreases, and it increases with an increase in the proportion of both olive root fiber and coir pith micro-particles. Moreover, from Figure 8b, it can be concluded that there is a linear decrease in density after exposure to the outdoor environment based on both the proportion of olive root fibers and coir pith micro-particles. However, the proportion of polyester waste fiber shows a negligible effect on the loss of density of hybrid composites when exposing them to the outdoor environment. Generally, the density of each composite sample decreases but with a different percentage after exposure. As the incorporation of polyester waste fiber decreases and the proportion of olive root fiber and coir pith micro-particles increases, there is a substantial decrement of density.

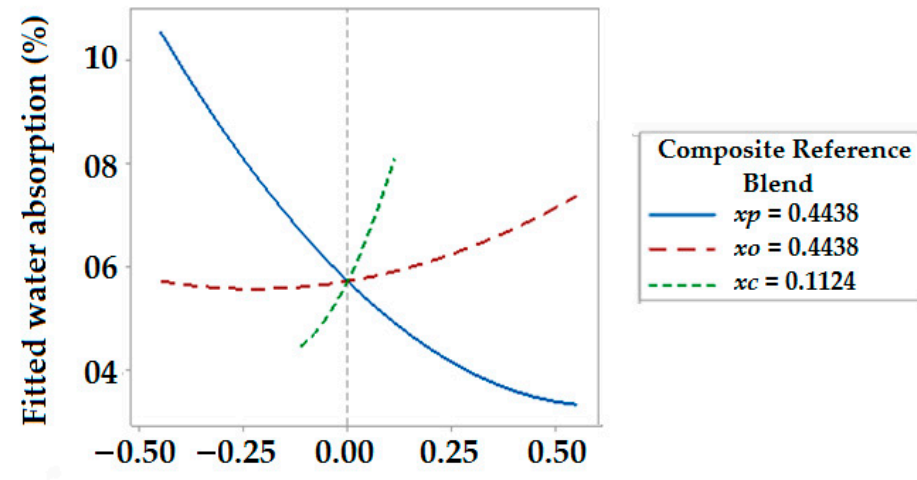

Deviation from reference blend proportion

(a)

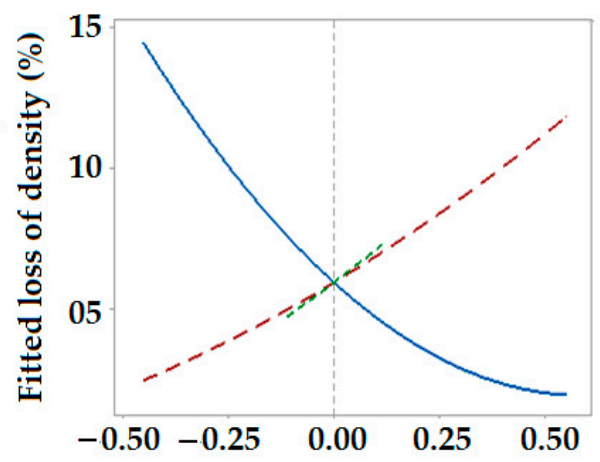

Deviation from reference blend proportion

(b)

Figure 8. Response trace plot for (a) water absorption (\%), (b) percentage decrease in density.

\subsubsection{Contour Plots for Environmental/Weathering Related Properties}

Figure 9a shows a contour plot for the water absorption properties of hybrid composites. Moving along the contour plot, it can be observed that the minimum value is indicated in the green region dominated by $X p$ (polyester waste fiber). When moving from this region towards the $X o$ (olive root proportion) and $X c$ (coir pith filler) region, the water absorption increases which is indicated by darker red color. The lowest value as given in Table 4 is about $3.24(\%)$ for the sample $\mathrm{C} 1$ of $(X p=100, X o=0.00, X c=0.00)$. Water absorption behavior increases with the increasing proportion of olive root fiber and coir pith micro-particle filler in the hybrid composite. In practical terms, these natural origin 
fibers and micro-particles are much more hygroscopic as compared to polyester fibers. The maximum water absorption of hybrid composite was about $10.92 \%$ for the sample C12 $\left(\mathrm{Xp}=0.00, \mathrm{Xo}_{\mathrm{N}}=77.52, \mathrm{Xc}_{\mathrm{c}}=22.48\right)$.
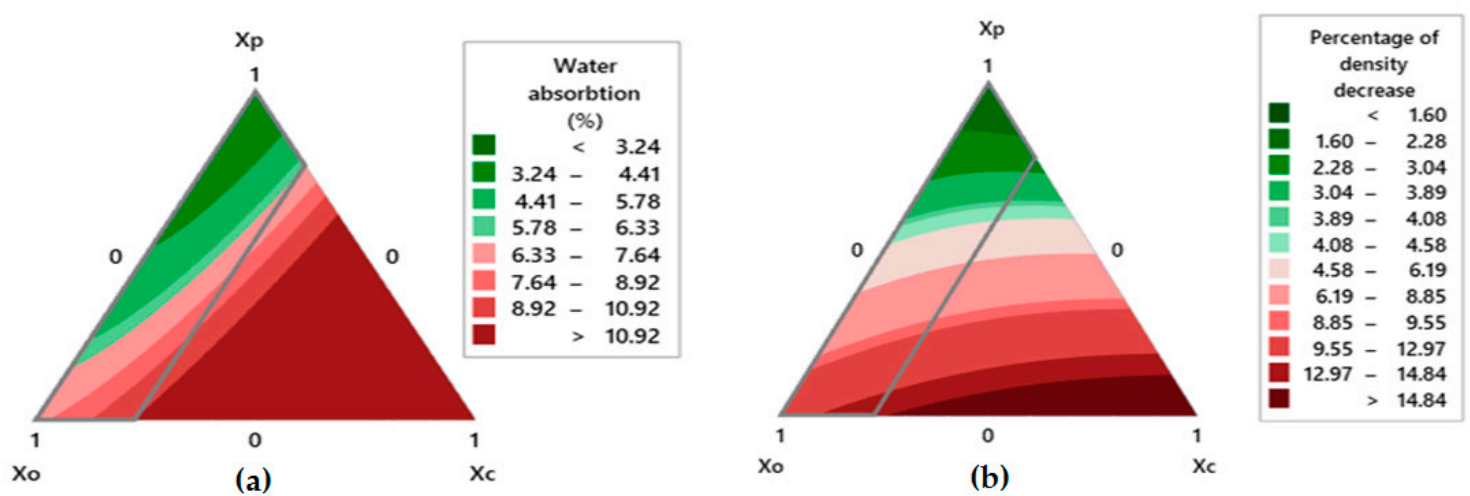

Figure 9. Contour plot for (a) water absorption (\%), (b) percentage loss of density.

The impact of weathering treatment on the percentage loss of density can be noted in Figure $9 \mathrm{~b}$. The maximum decrease in the density can be seen in the darker red region and the edge of Xo and Xc contour plot. The indication of lower density loss was given in the darker green region at the edge of $X p$. Maximum value for density loss was about $14.84 \%$ for the sample $\mathrm{C} 12(X p=0.00, X o=77.52, X c=22.48)$ and the minimum value for the density loss was about $1.60 \%$ for sample $\mathrm{C} 1(X p=100, X o=0.00, X c=0.00)$. The polyester fiber is least degradable which leads to minimum density loss. Biological origin materials, e.g., olive root fibers or coir pith micro-particles are susceptible to degradation and loss of density. Due to weathering, some of the fibers and micro-particles are degraded and this leads to loss of weight. Further, the volume is found to increase causing a loss of density.

Figures 10 and 11 show the variations of water absorption and change in density before and after weathering for all the hybrid composite samples as compared to fiber glass sunshade panels.

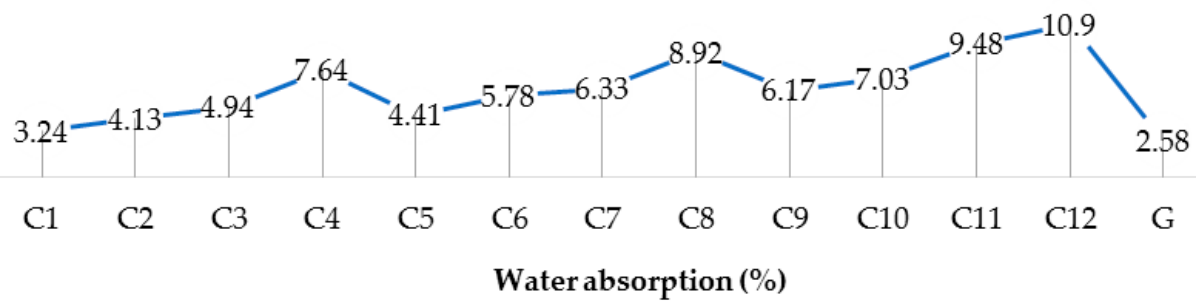

Figure 10. Water absorption (\%) of hybrid composites.

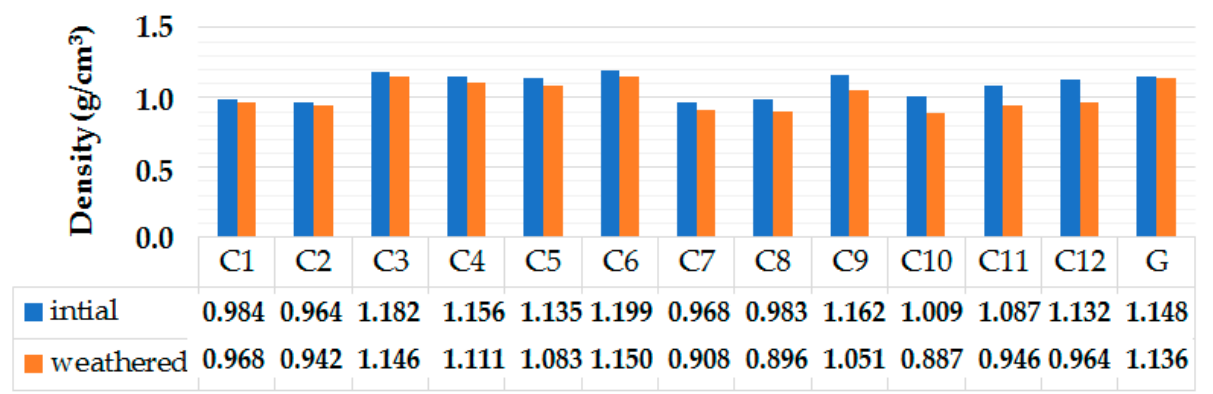

Figure 11. Densities of hybrid composite before and after weathering. 


\subsubsection{Surface Damage after Weathering Treatment}

After weathering treatment, the changes on the surface of each hybrid composite were visually examined. It was observed that the hybrid composite samples having olive root fibers and coir pith micro-particles as major constituents resulted in more surface degradation as compared to composite samples containing polyester waste fibers as a major constituent. Moreover, coir pith micro-particles and olive root fibers protruded on the surface of the composite samples. This is due to the degradation of olive root fibers and coir pith during weathering treatment. Moreover, the observed higher loss in the density of such hybrid composites based on the major proportion of olive root fibers and coir pith micro-particles can be due to the effect of moisture and UV radiation on cellulose, lignin and hemicellulose in these biological origin materials. The hybrid composites rich in cellulosic components degraded due to exposure to a combination of xenon arc radiation and water spray. However, the resistance to environmental degradation of such hybrid composites is significantly improved by increasing the proportion of PET fibers in the composite [23].

\subsection{Analysis of Variance for Thermal Properties}

ANOVA of the thermal expansion properties in hybrid composites is given in Table 7.

The results indicate that the quadratic model is a suitable model to fit the thermal expansion behavior of hybrid composites. It predicts the thermal expansion response with a probability value of $p=86 \%$. Two-component interaction $X p^{*} X o$ has a probability of $p=74 \%$ and thus this interaction has a relatively insignificant effect on the thermal response. While two-component interactions of $X p^{*} X c$ and $X o^{*} X c$ show a significant influence on thermal expansion properties of hybrid composite with a probability value of $p=96 \%$ and $p=94 \%$ respectively. Therefore, the quadratic model is a relatively good choice to fit the coefficient of thermal expansion as compared to the linear model. The thermal expansion in a composite system is governed by the Halpin-Tsai models and the hybrid composites in the present investigation follow a similar trend [32,33]. The matrix constitutes the majority component in the composites and thus the thermal properties are dominated by the matrix thermal properties. The addition of micro-particles restricts the thermal deformations in the hybrid composites. Since polyester fiber is thermoplastic in nature, a higher proportion always leads to higher deformation in response to thermal conditions. On the other hand, the presence of a higher proportion of cellulosic fiber like olive root fibers restricts thermal deformation.

\subsubsection{Normal Probability Plot of Residuals for Thermal Properties}

A residual normal probability plot for the coefficient of thermal expansion (CTE), as seen in Figure 12, indicates that five data points out of twelve data points fall very close to the fitted slope line. The remaining points are distributed in groups very close to each other and also close to the probability line. Residual normal probability plot thus validates the distribution of coefficient of a thermal expansion near to normal distribution.

\subsubsection{Response Trace Plot for Thermal Properties}

As shown in Figure 13, the response trace plot for the thermal expansion of hybrid composites concludes that the two-component interaction of polyester waste fiber with olive root fiber $\left(\mathrm{Xp} p^{*} \mathrm{Xo}\right)$ affects a linear decrement in the thermal expansion behavior of samples to an optimum level. After that the hybrid composites start to expand. Moreover, the addition of coir pith micro-particles enables a linear decrement of thermal expansion coefficient in composites. Both the reinforcing fibers as well as the micro-particle filler provide restrictions to the expansion of the composite by offering resistance at the interfacial region with the matrix. Such behavior is well established by theoretical models using the rule of the mixture as well as modified Halpin-Tsai equations [32,33]. 


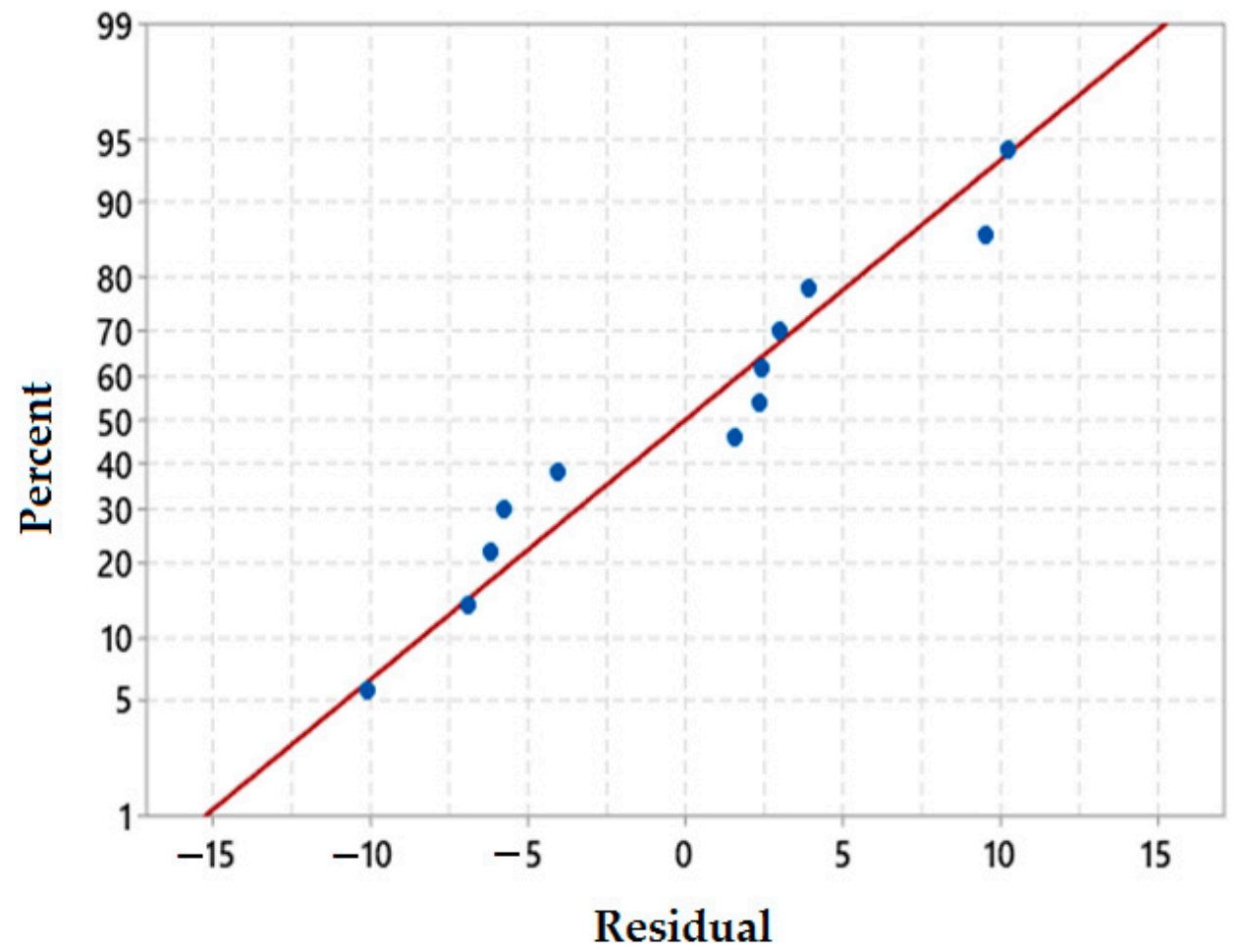

Figure 12. Residual normal probability plot of CTE.

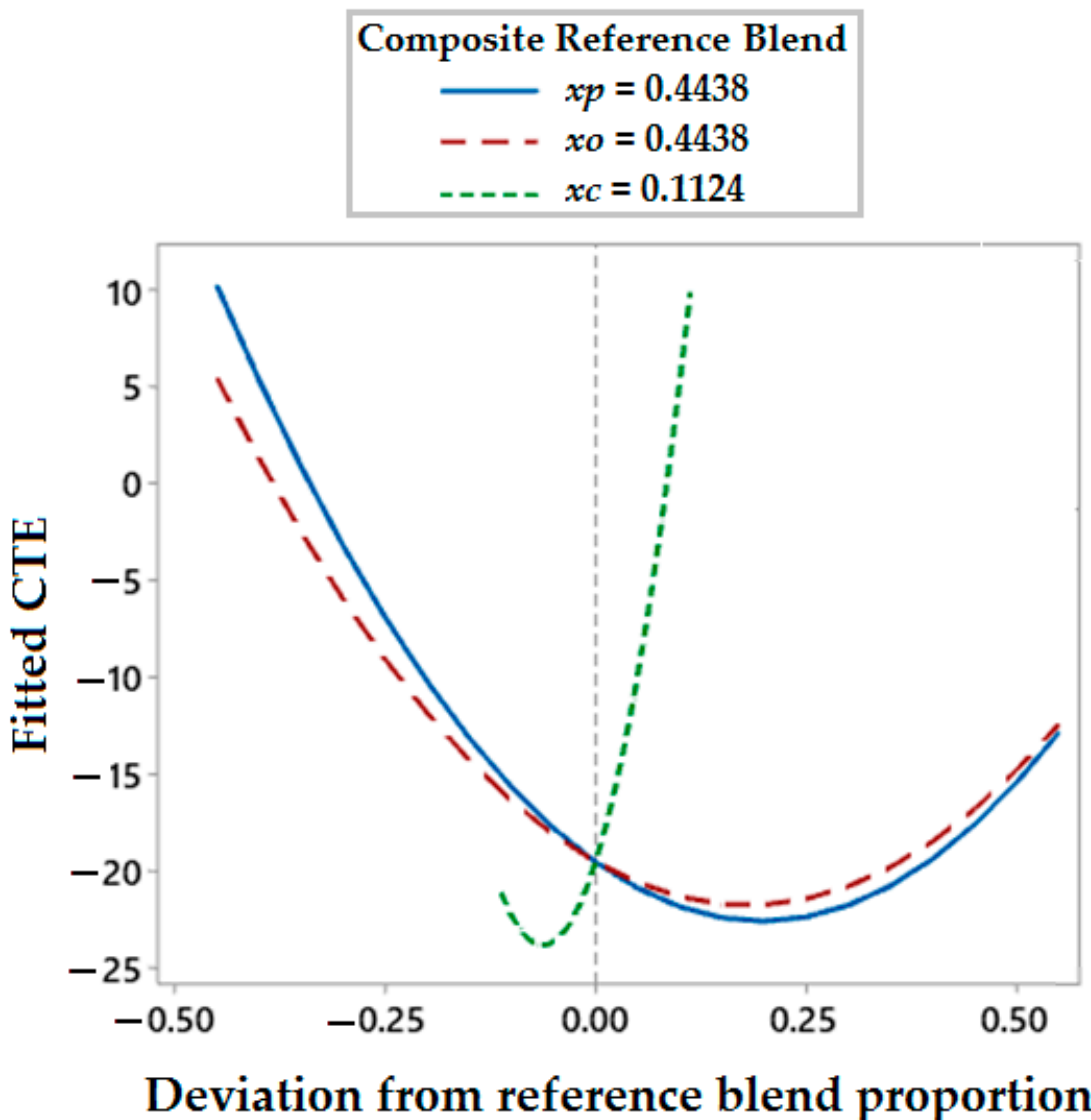

Figure 13. Response trace plot of CTE. 


\subsubsection{Contour Plot for Thermal Response}

For the thermal expansion behavior, the contour plot is shown in Figure 14.

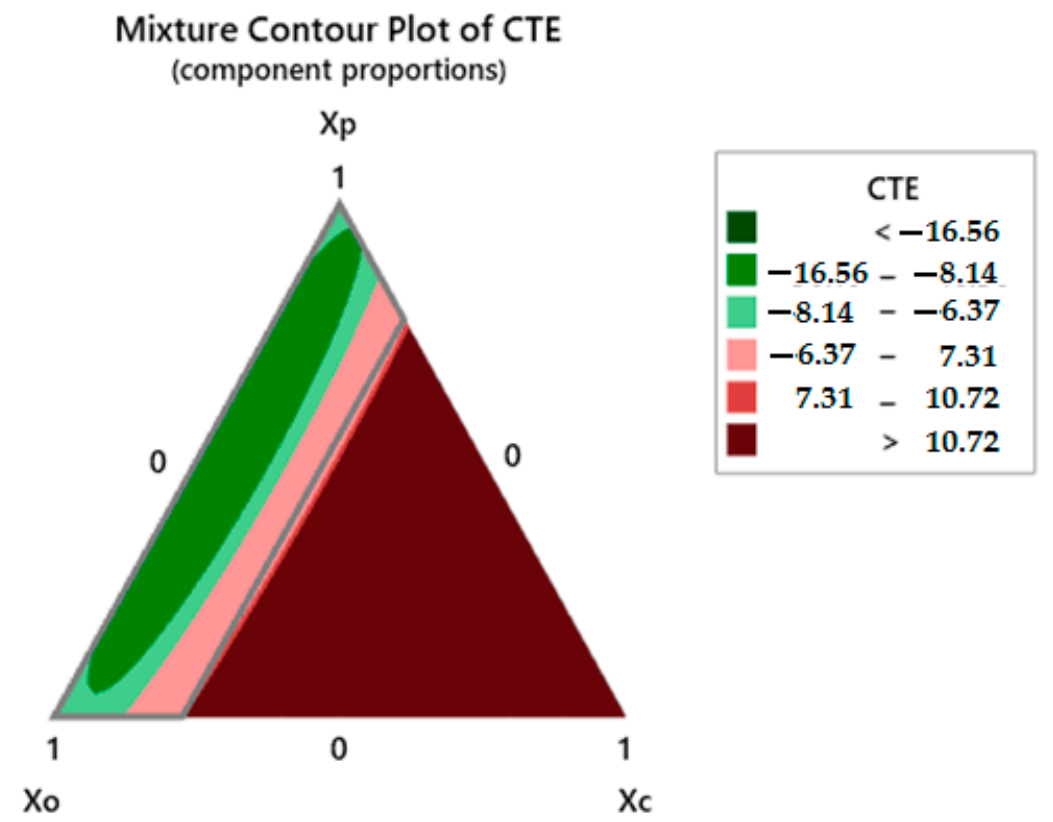

Figure 14. Coefficient of thermal expansion for hybrid composites.

A higher proportion of $X p$ (polyester waste fiber) offers a negative coefficient of thermal expansion. This tendency of negative thermal expansion was observed for the samples $\mathrm{C} 1$ to $\mathrm{C} 8$ as shown in Tables 3 and 4 . The minimum negative thermal expansion value was observed for sample $\mathrm{C} 8$. These trends indicate that reinforcing fibers actually cause a thermal shrinkage. The shrinkage is reduced as the polyester fiber proportion is reduced. As polyester is a thermoplastic fiber material, it might deform during the increase in temperature and cause this shrinkage. On the other hand, olive root fibers are plant-origin cellulosic materials. They do not tend to deform as the temperature rises. The hybrid composites containing polyester waste fibers, exhibit expansion in linear trend from $25-75{ }^{\circ} \mathrm{C}$. As the temperature further increases, the rate of contraction in the composite increases constantly up to $150^{\circ} \mathrm{C}$ and the coefficient of thermal expansion turns negative. However, the hybrid composites containing a major proportion of olive root fibers and coir pith micro-particles in the mixture expand linearly up to $150{ }^{\circ} \mathrm{C}$ and show relatively lower coefficients of thermal expansion. These observations indicate that biological origin (cellulosic) reinforcements and fillers provide thermal stability and shape retention to a hybrid composite as opposed to thermoplastic fibers like polyester. Guangfa et.al also observed that polyester fiber starts to contract and the coefficient of thermal expansion turns into a negative value as the temperature increased above $220^{\circ} \mathrm{C}$ [42].

\subsection{Thermogravimetric Analysis of Hybrid Composites and Composites}

TGA (Thermo-Gravimetric Analysis) results of the hybrid composites describe the thermal stability at elevated temperatures. It can be observed that thermal stability is significantly affected by a mixture of polyester waste fiber, olive root fiber and coir pith micro-particles. The TGA curves shown in Figure 15 explain the weight loss at the onset of thermal degradation. 


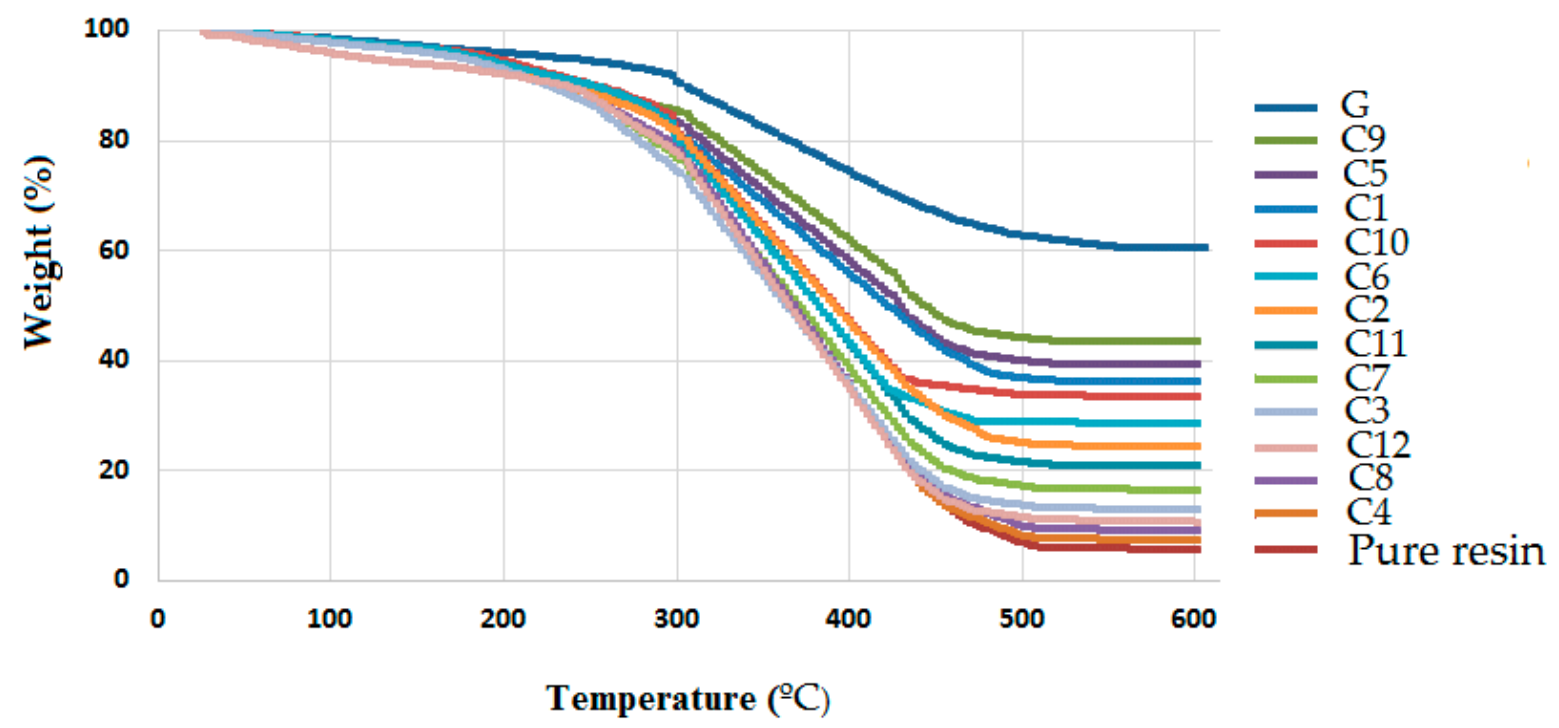

Figure 15. TGA-curves of hybrid composites.

The TGA results of composite samples as shown in Figure 15 indicate weight loss of $0.3 \%$ to $6 \%$ of the original weight between $100{ }^{\circ} \mathrm{C}$ and $200{ }^{\circ} \mathrm{C}$ respectively due to elimination of moisture in the matrix. At about $450{ }^{\circ} \mathrm{C}$, the weight loss was between $15 \%$ to $57 \%$ due to the degradation and volatilization of some components in the matrix. Subsequently, there is no further loss of weight up to $600{ }^{\circ} \mathrm{C}$. This trend is visible for all the hybrid and non-hybrid composites as well as composites in the present study.

It can be stated that the thermal stability of hybrid composites is significantly influenced by the matrix and different reinforcement materials in the component mixture. The thermal decomposition takes place in a three-step process for each composite sample as can be seen in the TGA curves. The decomposition temperature for the olive root fiber-based composite samples was lower than the pure polyester fiber-based samples. This may be due to higher moisture content and volatile substances in natural origin cellulosic fibers as compared to polyester fibers. In the first stage, a small mass loss was observed for all samples between $210^{\circ} \mathrm{C}$ to $310^{\circ} \mathrm{C}$ due to the degradation of organic elements in the composites. For the second stage of decomposition, in the temperature range from $310^{\circ} \mathrm{C}$ to $370{ }^{\circ} \mathrm{C}$, the hemicellulose component in the olive root fiber may be responsible. The third peak at about $420{ }^{\circ} \mathrm{C}$ was mainly due to the degradation of the unsaturated polyester matrix.

Table 8 shows the maximum temperature of decomposition, mass loss (\%) and char (\%) at $600{ }^{\circ} \mathrm{C}$ for all the samples.

Table 8. TGA results for hybrid composites.

\begin{tabular}{cccc}
\hline Samples & $\mathbf{T}$ MAX $\left({ }^{\circ} \mathbf{C}\right)$ & Mass Loss $(\%)$ & Char $(\mathbf{\%})$ at $\mathbf{6 0 0}{ }^{\circ} \mathbf{C}$ \\
\hline C1 & 454 & 62 & 38 \\
C2 & 438 & 75 & 25 \\
C3 & 433 & 82 & 18 \\
C4 & 432 & 90 & 10 \\
C5 & 456 & 58 & 42 \\
C6 & 440 & 69 & 31 \\
C7 & 436 & 80 & 20 \\
C8 & 433 & 86 & 14 \\
C9 & 457 & 55 & 45 \\
C10 & 448 & 65 & 35 \\
C11 & 438 & 78 & 22 \\
C12 & 436 & 84 & 16 \\
G & 467 & 38 & 62 \\
\hline
\end{tabular}


The hybrid composites show changes in the process of decomposition due to varying component interactions. The composites with a higher proportion of polyester waste fibers show better thermal stability up to a higher peak temperature of degradation. Hybridization with cellulosic fibers reduces the peak decomposition temperature. On the other hand, the addition of scale fillers in the matrix improves thermal stability. This is mainly because the micro-particles derived from cellulosic fibers, e.g., coir are free from volatile components. These micro-particles are highly crystalline and are free from moisture. The incorporation of scale fillers enables dissipation of heat in the composite system and the degradation is prohibited up to a higher temperature level. When the proportion of micro-fillers was increased from $5 \%$ to $10 \%$, a further increase in peak temperature was observed.

The mass loss was observed to be reduced by the hybridization of polyester and olive root fibers. Mass loss in polyester-rich composites was lower as compared to olive root fiber-rich samples. The combination of PET and cellulosic materials in a hybrid composite works in a synergistic manner and they compensate and complement the weaknesses of each other. The use of micro-particles from cellulose origin materials proves to be beneficial in order to improve thermal stability and reduce overall mass loss at elevated temperatures.

The mass loss (\%) of the hybrid composites, as well as composites, was higher as compared to commercial fiber glass sunshade panels though the glass panel exhibits a slightly higher peak temperature of degradation.

\subsection{Optimization for all Responses}

The optimal mechanical properties (tensile strength, flexural strength and impact strength), environmental/weathering properties (water absorption and density loss) and the thermal properties (coefficient of thermal expansion) of the hybrid composites were estimated using an optimization approach for each dependent response. The mechanical responses were maximized, environmental properties and thermal expansion properties were minimized. By using this approach, the best combination was found to be $X p=70.83 \%$, $X o=15.16 \%$ and $X c=14.01 \%$.

\section{Conclusions}

In this study, an attempt was made to fabricate hybrid composite materials using polyester waste fibers, olive root fibers and coir pith particles as reinforcement in unsaturated polyester resin. Micro-particles obtained from coir pith by ball milling process were used as filler in the polyester resin. The mechanical, thermal, and weathering-related properties were determined for all fabricated hybrid and non-hybrid composite samples. These hybrid composites were then compared with commercial glass fiber-based composite panels used as a sunshade in interior applications.

Mixture design analysis was used to optimize the component proportions in the hybrid composite. For all mechanical responses (tensile strength, flexural strength, and impact strength) environmental properties (water absorption and density loss after weathering) and for the coefficient of thermal expansion, statistical models were developed which show good validity with experimental results. The best formulation was determined at $70.83 \mathrm{wt} \%, 15.16 \mathrm{wt} \%$ and $14.01 \mathrm{wt} \%$ of polyester waste fibers, olive root fibers and coir pith fillers, respectively.

Among all the hybrid composites, sample $\mathrm{C} 6$ showed the maximum tensile strength and maximum flexural strength. In comparison with commercial glass fiber-based composite, sample C6 reached $30.42 \%$ of its tensile strength and almost half of its flexural strength. Maximum tensile strength, flexural strength and impact strength in the developed hybrid composite can be achieved by optimum mixture ratio of polyester waste fiber, olive root fiber and coir pith micro-particles.

The maximum impact strength of the developed hybrid composites was obtained in samples C9 and C10. However, by comparison with commercially available glass fiber composite, C9 composite showed almost $15 \%$ of its impact strength. The impact strength 
increased as the mixture proportion of polyester waste fiber and coir pith micro-particles was increased.

With respect to the environmental/weathering-related properties, C1, C5, and C9 showed the minimum water absorption $\%$ as well as density loss which is almost nearer to the commercially available glass fiber composite. Comparing the water absorbency of commercially available glass fiber composite and the developed composite sample (C1), it is found that there is a minute difference in their water absorption capacity. The commercially available glass fiber panel loses $1.2 \%$ of its density after weathering while the developed composite $\mathrm{C} 1$ lost $1.6 \%$ of its density. From the results, it was found that the developed hybrid composite containing a major proportion of polyester waste fiber along with other cellulosic components can be preferred for outdoor applications.

At $150{ }^{\circ} \mathrm{C}$, sample $\mathrm{C} 12$ showed the minimum value of thermal expansion. The hybrid composite sample $\mathrm{C} 9$ containing a major proportion of polyester waste fiber and coir pith micro-particles in the mixture results in a minimum weight loss (\%) and a maximum char $(\%)$ at $600{ }^{\circ} \mathrm{C}$ as per the TGA results. It resulted in $45 \%$ residual char as against the commercial glass fiber composite giving about $62 \%$ char. Based on mechanical, thermal and weathering properties, the hybrid composites from polyester waste fiber, olive root fiber and coir pith micro-particles can be categorized separately for outdoor (sunshade) and indoor (interior) applications. These can be used in construction and structural applications at the same time addressing issues of waste management and eco-friendliness.

Author Contributions: M.R.T., H.J., R.M., U.H., M.T. and M.M. experiment design; M.R.T., H.J., R.M., U.H. and M.T. testing of mechanical properties and data analysis; M.R.T., H.J., R.M., U.H., M.T. and M.M. wrote and edited the paper; H.J., R.M. and M.M. language correction; R.M. communication with the editors; H.J., R.M., M.T. and M.M. administration and funding; All authors have read and agreed to the published version of the manuscript.

Funding: The work was supported by the internal grant agency of the Faculty of Engineering, Czech University of Life Sciences Prague (No. 2021:31140/1312/3108).

Institutional Review Board Statement: Not applicable.

Informed Consent Statement: Not applicable.

Data Availability Statement: Not applicable.

Conflicts of Interest: The authors declare no conflict of interest.

\section{References}

1. Belgacem, M.N.; Gandini, A. The surface modification of cellulose fibres for use as reinforcing elements in composite materials. Compos. Interfaces 2005, 12, 41-75. [CrossRef]

2. Masuelli, M. Fiber Reinforced Polymers: The Technology Applied for Concrete Repair; Intech Open Limited: London, UK, 2013.

3. Valadez-Gonzalez, A.J.; Olayo, C.; Herrera-Franco, P. Effect of fiber surface treatment on the fiber-matrix bond strength of natural fiber reinforced composites. Compos. Part B Eng. 1999, 30, 309-320. [CrossRef]

4. Gibson, R.F. Principle of Composite Material Mechanics, 3rd ed.; CRC Press: Boca Raton, FL, USA, 2011.

5. Joshi, S.V.; Drzal, L.; Mohanty, A.; Arora, S. Are natural fiber composites environmentally superior to glass fiber reinforced composites? Compos. Part A Appl. Sci. 2004, 35, 371-376. [CrossRef]

6. Mohanty, A.K.; Misra, M.; Drzal, L.T. Natural Fibers, Biopolymers, and Biocomposites; CRC Press Taylor and Francis: London, UK, 2005.

7. Faruk, O.; Bledzki, A.K.; Fink, H.P.; Sain, M. Progress report on natural fiber reinforced composites. Macromol. Mater. Eng. 2014, 299, 9-26. [CrossRef]

8. Saheb, D.N.; Jog, J.P. Natural fiber polymer composites: A review. Adv. Polym. Tech. J. Polym. Proc. Inst. 1999, 18, 351-363. [CrossRef]

9. Mohanty, A.; Misra, M.; Drzal, L.T. Surface modifications of natural fibers and performance of the resulting biocomposites: An overview. Compos. Interfaces 2001, 8, 313-343. [CrossRef]

10. Mishra, R.; Gupta, N.; Pachauri, R.; Behera, B.K. Modelling and simulation of earthquake resistant 3D woven textile structural concrete composites. Compos. Part B Eng. 2015, 81, 91-97. [CrossRef]

11. Dashtizadeh, Z.; Abdan, K.; Jawaid, M.; Khan, M.; Behmanesh, A.M.; Dashtizadeh, M.; Cardona, F.; Ishak, M. Mechanical and thermal properties of natural fibre based hybrid composites: A review. Pertanika J. Sci. Technol. 2017, 25, 1103-1122.

12. Gururaja, M.; Rao, A.H. A review on recent applications and future prospectus of hybrid composites. Int. J. Soft Comput. Eng. 2012, 1, 352-355. 
13. Franciszczak, P.; Piesowicz, E.; Kalniňš, K. Manufacturing and properties of r-PETG/PET fibre composite-Novel approach for recycling of PETG plastic scrap into engineering compound for injection moulding. Compos. Part B Eng. 2018, 154, 430-438. [CrossRef]

14. Wu, C.; Hsieh, W.; Su, S.; Cheng, K.; Lee, K.; Lai, C. Study of braiding commingled self-reinforced PET composites. Int. J. Mod. Phy. B 2018, 32, 1840086. [CrossRef]

15. Ahmad, M.; Majid, M.; Ridzuan, M.; Firdaus, A.; Amin, N. Tensile properties of interwoven hemp/PET (Polyethylene Terephthalate) epoxy hybrid composites. J. Phy. Conf. Series. 2017, 908, 012011. [CrossRef]

16. Dan-mallam, Y.; Abdullah, M.Z.; Yusoff, P. Mechanical properties of recycled kenaf/polyethylene terephthalate (PET) fiber reinforced polyoxymethylene (POM) hybrid composite. J. Appl. Polym. Sci. 2014, 131. [CrossRef]

17. Wu, C.; Lin, P.; Murakami, R. Long-term creep behavior of self-reinforced PET composites. Exp. Polym. Lett. 2017, 11. [CrossRef]

18. Narendar, R.; Dasan, K.P. Development of coir pith based hybrid composite panels with enhanced water resistant behavior. Environ. Prog. Sust. Energy 2015, 34, 1481-1487. [CrossRef]

19. Essabir, H.; Bensalah, M.; Rodrigue, D.; Bouhfid, R.; Qaiss, A. Structural, mechanical and thermal properties of bio-based hybrid composites from waste coir residues: Fibers and shell micro-particles. Mech. Mater. 2016, 93, 134-144. [CrossRef]

20. Islam, M.T.; Das, S.C.; Saha, J.; Paul, D.; Islam, M.T.; Rahman, M.; Khan, M.A. Effect of coconut shell powder as filler on the mechanical properties of coir-polyester composites. Chem. Mate.r Eng. 2017, 5, 75-82. [CrossRef]

21. Narendar, R.; Dasan, K.P. Effect of chemical treatment on the mechanical and water absorption properties of coir pith/nylon/epoxy sandwich composites. Int. J. Polym. Anal. Char. 2013, 18, 369-376. [CrossRef]

22. Jamshaid, H.; Mishra, R.; Pechociakova, M.; Noman, M.T. Mechanical, thermal and interfacial properties of green composites from basalt and hybrid woven fabrics. Fiber Polym. 2016, 17, 1675-1686. [CrossRef]

23. Prithivirajan, R.; Jayabal, S.; Sundaram, S.K.; Kumar, A.P. Hybrid bio composites from agricultural residues: Mechanical and thickness swelling behavior. Int. J. Chem. Tech. Res. 2016, 9, 609-615.

24. Mishra, R.; Huang, J.; Kale, B.; Zhu, G.; Wang, Y. The production, characterization and applications of nanoparticles in the textile industry. Textile Prog. 2014, 46, 133-226. [CrossRef]

25. Dehas, W.; Guessoum, M.; Douibi, A.; Jofre-Reche, J.A.; Martin-Martinez, J.M. Thermal, mechanical, and viscoelastic properties of recycled poly (ethylene terephthalate) fiber-reinforced unsaturated polyester composites. Polym. Compos. 2018, 39, 1682-1693. [CrossRef]

26. Abdullah, M.Z.; Dan-mallam, Y.; Yusoff, P. Effect of environmental degradation on mechanical properties of kenaf/polyethylene terephthalate fiber reinforced polyoxymethylene hybrid composite. Adv. Mater. Sci. Eng. 2013, 2013, 671481. [CrossRef]

27. Dan-Mallam, Y.; Abdullah, M.Z.; Yosuff, P. Impact strength, microstructure, and water absorption properties of kenaf/polyethylene terephthalate (PET) fiber-reinforced polyoxymethylene (POM) hybrid composites. J. Mater. Res. 2013, 28, 2142-2146. [CrossRef]

28. Amir, M.; Irmawaty, R.; Hustim, M.; Rahim, I. Tensile strength of glass fiber-reinforced waste PET and Kenauf hybrid composites. In Proceedings of the IOP Conference Series Earth and Environmental Science, Bali, Indonesia, 29-30 August 2020; Volume 419, p. 012061. [CrossRef]

29. Ayrilmis, N.; Buyuksari, U. Utilization of olive mill sludge in manufacture of lignocellulosic/polypropylene composite. J. Mater. Sci. 2010, 45, 1336-1342. [CrossRef]

30. Raghavarao, D.; Wiley, J.B.; Chitturi, P. Choice-Based Conjoint Analysis: Models and Designs; CRC Press: Boca Raton, FL, USA, 2010.

31. Zhang, C.; Wong, W.K. Optimal designs for mixture models with amount constraints. Stat. Prob. Lett. 2013, 83, 196-202. [CrossRef]

32. Tucker, C.L.; Liang, E. Stiffness predictions for unidirectional short-fiber composites: Review and evaluation. Compos. Sci. Technol. 1999, 59, 655-671. [CrossRef]

33. Halpin Affdl, J.C.; Kardos, J.L. The Halpin-Tsai equations: A review. Polym. Eng. Sci. 1976, 16, 344-352. [CrossRef]

34. Makarian, K.; Santhanam, S.; Wing, Z.N. Coefficient of thermal expansion of particulate composites with ceramic inclusions. Ceram. Int. 2016, 42, 17659-17665. [CrossRef]

35. Karch, C. Micromechanical analysis of thermal expansion coefficients. Model. Numer. Simul. Mater. Sci. 2014, 4, 104-119. [CrossRef]

36. Safi, M.; Hassanzadeh-Aghdam, M.K.; Mahmoodi, M.J. Effects of nano-sized ceramic particles on the coefficients of thermal expansion of short SiC fiber-aluminum hybrid composites. J. Alloys Compd. 2019, 803, 554-564. [CrossRef]

37. Cornell, J.A. Experiments with Mixtures: Designs, Models, and the Analysis of Mixture Data; John Wiley \& Sons: Hoboken, NJ, USA, 2011.

38. Oehlert, G.W. A First Course in Design and Analysis of Experiments; University of Minnesota: Minneapolis, MN, USA, 2010.

39. Rostamiyan, Y.; Mashhadzadeh, A.H.; Khani, A.S. Optimization of mechanical properties of epoxy-based hybrid composite: Effect of using silica and high-impact polystyrene by mixture design approach. Mater. Des. 2014, 56, 1068-1077. [CrossRef]

40. Dehghani, A.; Ardekani, S.M.; Al-Maadeed, M.A.; Hassan, A.; Wahit, M.U. Mechanical and thermal properties of date palm leaf fiber reinforced recycled poly (ethylene terephthalate) composites. Mater. Des. 2013, 52, 841-848. [CrossRef]

41. Nagaraj, C.; Mishra, D.; Reddy, J.D. Estimation of tensile properties of fabricated multi layered natural jute fiber reinforced E-glass composite material. Mater. Today Proc. 2020, 27, 1443-1448. [CrossRef]

42. Guangfa, G.; Shujie, Y.; Ruiyuan, H.; Yongchi, L. Experimental investigation on thermal physical properties of an advanced polyester material. Phy. Proc. 2012, 25, 333-338. [CrossRef] 